\title{
Determination of the saturated film conductivity to improve the EMFX model in describing the soil hydraulic properties over the entire moisture range
}

\author{
Yunquan Wang ${ }^{1}$, Jinzhu $\mathrm{Ma}^{2}$, Huade Guan ${ }^{3}$, Gaofeng Zhu ${ }^{2}$, \\ ${ }^{1}$ School of Environmental Studies, China University of Geosciences at Wuhan, 430074 \\ ${ }^{2}$ Key Laboratory of Western China's Environmental Systems (Ministry of Education), Lanzhou \\ University, 222 South Tianshui Road, Lanzhou 730000, China \\ ${ }^{3}$ School of the Environment and National Centre for Groundwater Research and Training, Flinders \\ University of South Australia, Australia
}

*Corresponding Author: Yunquan Wang, School of Environmental Studies, China University of Geosciences at Wuhan, Lumo Rd.388, Hongshan District, Wuhan, China, 430074 (wangyq@cug.edu.cn)

\begin{abstract}
Difficulty in measuring hydraulic conductivity, particularly under dry conditions, calls for methods of predicting the conductivity from easily obtained soil properties. As a complement to the recently published EMFX model, a method based on two specific suction conditions is proposed to estimate saturated film conductivity from the soil water retention curve. This method reduces one fitting parameter in the previous EMFX model, making it possible to predict the hydraulic conductivity from the soil water retention curve over the complete moisture range. Model performance is
\end{abstract}


evaluated with published data of soils in a broad texture range from sand to clay. The testing results indicate that 1 ) the modified EMFX model (namely the EMFX-K model), incorporating both capillary and adsorption forces, provides good agreement with the conductivity data over the entire moisture range; 2) a value of 0.5 for the tortuosity factor in the EMFX-K model as that in the Mualem's model gives comparable estimation of the relative conductivity associated with the capillary force; and 3) a value of $-1.0 \times 10^{-20} \mathrm{~J}$ for the Hamaker constant, rather than the commonly

used value of $-6.0 \times 10^{-20} \mathrm{~J}$, appears to be more appropriate to represent solely the effect of the van der Waals forces and to predict the film conductivity. In comparison with the commonly used van Genuchten-Mualem model, the EMFX-K model significantly improves the prediction of hydraulic conductivity under dry conditions. The sensitivity analysis result suggests that the uncertainty in the film thickness estimation is important in explaining the model underestimation of hydraulic conductivity for the soils with fine texture, in addition to the uncertainties from the measurements and the model structure. High quality data that cover the complete moisture range for a variety of soil textures are required to further test the method.

Keywords: The EMFX model; Hydraulic conductivity; Soil water retention curve; Film flow; Unsaturated porous media

\section{Introduction}

Determination of unsaturated soil hydraulic properties (soil water retention and hydraulic conductivity) is crucial in modeling and predicting water flow and solute 
transport in vadose zone. Since direct measurement, especially under low water content conditions, is time consuming and sometimes impractical (Vereecken et al., 2010), many pedotransfer functions (PTFs) have been proposed to estimate the soil water retention curve (SWRC) from easily measurable soil properties (e.g., the grain size distribution and the bulk density), while the hydraulic conductivity function can be predicted from the SWRC (see reviews in Pachepsky and Rawls, 2004; Vereecken et al., 2010). Although they have been used widely, the performance of these PTFs and the predicted hydraulic conductivity functions is far from satisfying under low water content conditions (Weynants et al., 2009; Schaap and van Genuchten, 2006).

Conceptual simplification of soil pores as a bundle of capillary tubes is widely accepted in the soil hydraulic model development (Mualem 1976a; van Genuchten 1980). This theory based on the capillary force, however, has been questioned for neglecting the soil surface forces occurring in thin film on the soil particle surface ( $\mathrm{Li}$ and Wardlaw, 1986; Lenormand, 1990; Toledo et al., 1990). These adsorption forces, induced mainly by the ionic electrostatic forces and/or the van der Waals forces, are thought to be dominant under low water content conditions (Tuller and Or, 2001; Tokunaga, 2009, 2011; Wang et al., 2013). Therefore, the generally underestimation of hydraulic conductivity at low water contents in the capillary-theory based models (Silva and Grifoll, 2007) might be attributed to the neglect of the adsorption forces.

Including adsorption forces into soil hydraulic models was proposed nearly twenty years ago (Or and Tuller, 1999; Tuller et al., 1999; Tuller and Or, 2001). Since then, a series of hydraulic models, accounting for both capillary and film flow, have been 
developed (Lebeau and Konrad, 2010; Zhang, 2011; Peters, 2013; Wang et al., 2016). Despite the significant progress in model development (Durner et al., 2014), the application of such complete hydraulic models has not been widely accepted. In comparison with commonly used capillary-theory based soil hydraulic models, a complete hydraulic model that accounts for both capillary and film flow often requires an extra parameter, the saturated film conductivity (Peters, 2013; Wang et al., 2016), to describe the complete conductivity function. Given the difficulty in measuring the hydraulic conductivity under dry conditions, it is not easy to define the value of this parameter, limiting the usage of the complete models.

Lebeau and Konrad (2010) related the film conductivity function to the equivalent particle diameter, a parameter that reflects the surface roughness and particle non-uniformity and can be calculated from the SWRC. This method performs well when tested with the soils of a relatively coarse texture (Lebeau and Konrad, 2010). However, under low water content conditions, the SWRC used in Lebeau and Konrad (2010) yields somewhat poor agreement with the observations, thus, introduces uncertainty in predicting the film conductivity. Additionally, this method has not been tested with clay-rich soils where film water accounts for a high proportion of soil moisture (Hillel, 1982).

Recently, Wang et al. (2016) proposed a new complete SWRC model, namely the EMFX model, which describes the soil hydraulic properties over the entire moisture range. In comparison with the film models that based on the log-scale linear relationship of water content and matric suction (e.g., the Campbell and Shiozawa's 
model, 1992), the EMFX model performs better under dry conditions (Wang et al., 2016). To describe the conductivity function, however, the EMFX model requires an extra parameter (the saturated film conductivity) to represent the hydraulic conductivity corresponding to the residual water content conceptually which is beyond the influence of the capillary force. As a result, to determine the parameter value, the SWRC and the conductivity function have to be optimized with observations simultaneously. To facilitate the EMFX model application, in this paper, we 1) present a method for predicting the saturated film conductivity from the SWRC in the EMFX model, and 2) test the method with a broad data set of different soils ranging from sand to clay. In this method, the saturated film conductivity is estimated from two specific suction conditions, following a similar path of thinking as described in Lebeau and Konrad (2010).

\section{Theory and methods}

\subsection{The EMFX model}

The EMFX model developed recently by Wang et al., (2016) is an extension and modification of the Fredlund and Xing's model (1994). The model uses an empirical equation to express the soil water retention curve. The equation is mathematically continuous over the complete moisture range. The hydraulic conductivity is expressed as a combination of the capillary- and film-supported conductivity.

The soil water retention curve (SWRC) is written as

$$
S(h)=\Gamma(h)\left(\ln \left(e+|\alpha h|^{n}\right)\right)^{-m}
$$


where, $\mathrm{S}=\theta / \theta_{s}$ is the saturation degree, $\theta\left[\mathrm{L}^{3} \mathrm{~L}^{-3}\right]$ is the volumetric water content, $\theta_{s}$ is the saturated water content, $h(\mathrm{~L})$ is the matric suction, $\alpha\left(\mathrm{L}^{-1}\right), n$ and $m$ are all fitted parameters, $\Gamma(h)$ is a correction function defined as

$$
\Gamma(h)=1-\frac{\ln \left[1+c h / h_{r}\right]}{\ln \left[1+c h_{0} / h_{r}\right]}
$$

where $c$ is a constant with a value of $0.01, h_{r}$ is the matric suction corresponding to the residual water content $\theta_{r}$, and $h_{0}$, set to $6.3 \times 10^{6} \mathrm{~cm}$, is the matric suction at which water content is zero (Schneider and Goss, 2012). Note that, here, the residual water content means the moisture condition at which the capillary-form flow collapses.

As illustrated in Wang et al. (2016), this SWRC yields good agreement with the observations over the complete moisture range, and it has capacity to represent the bimodal hydraulic properties that are often present in structured and aggregated soils.

In the EMFX model, the hydraulic conductivity function that accounts for both capillary and adsorption forces is expressed as

$$
K= \begin{cases}K_{s} S_{c}^{l}\left[1-\left(\frac{1-S^{1 / m}}{1-S_{r}^{1 / m}}\right)^{1-1 / n}\right]^{2}+\left(1-S_{c}\right) K_{f}^{r}\left(\frac{2}{15}+\frac{13 h}{15 h_{r}}\right)^{-1.5} & \text { for } S \geq S_{r} \\ K_{f}^{r}\left(\frac{2}{15}+\frac{13 h}{15 h_{r}}\right)^{-1.5} & \text { for } S<S_{r}\end{cases}
$$

where $K\left[\mathrm{~L} \mathrm{~T}^{-1}\right]$ is the total hydraulic conductivity for liquid flow, $K_{s}$ is the hydraulic conductivity at saturation, $S_{r}=\theta_{r} / \theta_{s}$, is the saturation degree at the residual water content, $K_{f}^{r}$ is the film conductivity at $S_{r}$, defined as the saturated film conductivity, $S_{c}=\left(S-S_{r}\right) /\left(1-S_{r}\right)$ is the effective saturation where the capillary force dominates, $l$ is a parameter that accounts for tortuosity and connectivity, and is set to 0.5 according to Mualem (1976a). The parameters $n, m$, and $h_{r}$ can be determined from the SWRC, but 
the unknown parameter of $K_{f}^{r}$ makes it impossible to predict the relative conductivity function.

\subsection{The saturated film conductivity}

The saturated film conductivity $\left(K_{f}^{r}\right)$ in the EMFX model is difficult to measure. Here, following Lebeau and Konrad (2010), we present a method to estimate it from the SWRC.

Firstly, two parameters, the specific surface area, $A$, and the specific perimeter, $P$, are defined. Here, $A\left[\mathrm{~L}^{2} \mathrm{~L}^{-3}\right]$ is the volumetric surface area and $P\left[\mathrm{~L} \mathrm{~L}^{-2}\right]$ means the grain perimeter length per unit cross-sectional area (Tokunaga, 2009). Assuming the same grain diameter, $P$ should be equal to $2 A / \pi$ based on simple geometrical consideration (Lebeau and Konrad, 2010).

The saturated conductivity resulting from the film flow is (Bird et al., 1960)

$$
K_{f}^{r}=P \frac{\rho g}{3 \eta} f_{r}^{3}
$$

where $f_{r}$ is the film thickness at the suction of $h_{r}, \rho$ is the water density $\left(9.98 \times 10^{2} \mathrm{~kg}\right.$ $\left.\mathrm{m}^{-3}\right), g$ is the acceleration due to gravity $\left(9.81 \mathrm{~m} \mathrm{~s}^{-2}\right), \eta$ is the fluid viscosity $\left(1.005 \times 10^{-3} \mathrm{~Pa}\right.$ s at $\left.293 \mathrm{~K}\right)$.

While the existing model (e.g., the models presented in Iwamatsu and Horii, 1996; Tokunaga, 2009) generally gives good estimation of the film thickness (Resurreccion et al., 2011; Tokunaga, 2011), calculation of $P$ based on the smooth uniform grain assumption tends to underestimate that of real soils (Hillel, 1982). This is the main reason for treating $K_{f}^{r}$ as a free fitted parameter in the hydraulic conductivity models (e.g., the EMFX model). Here, we assume that the surface roughness and particle 
non-uniformity of real porous media are mainly represented in the parameter of the specific perimeter, $P$, while the smooth surface based film thickness-matric suction relationship (Iwamatsu and Horii, 1996; Tokunaga, 2011) is applicable for real soils. Then, the key problem in determining $K_{f}^{r}$ turns to determining the value of $P$, a fixed value for one specific soil.

At a specific matric potential, $h_{m}$, where water content is totally in the form of thin film, $A$ can be estimated as (Tuller and Or, 2005)

$$
A=\frac{\theta_{m}}{f_{m}}
$$

where $\theta_{m}$ and $f_{m}$ are the volumetric water content and film thickness corresponding to the suction of $h_{m}$, respectively.

Considering $P=2 A / \pi$ and substituting Eq. (5) into Eq. (4) gives

$$
K_{f}^{r}=\frac{2 \rho g \theta_{m}}{3 \pi \eta f_{m}} f_{r}^{3}
$$

When the matric suction is relatively low (i.e., the film is thick), the ionic-electrostatic forces are the dominant component, while the van der Waals forces become more important at very high matric suction (typically higher than $10^{2} \mathrm{~m}$, Lebeau and Konrad, 2010; Tokunaga, 2011). Therefore, the film thickness $f_{r}$ can be estimated for the condition when the ionic electrostatic forces dominate, expressed as (Tokunaga, 2009; 2011)

$$
f_{r}=\sqrt{\frac{\varepsilon \varepsilon_{0}}{2}}\left(\frac{\pi k_{B} T}{z e}\right)\left(\frac{4 \sigma}{\lambda}+\rho g h_{r}\right)^{-0.5}
$$

where $\varepsilon$ is the relative permittivity of water (78.54), $\varepsilon_{0}$ is the permittivity of free space $\left(8.85 \times 10^{-12} \mathrm{C}^{2} \mathrm{~J}^{-1} \mathrm{~m}^{-1}\right), k_{\mathrm{B}}$ is the Boltzmann constant $\left(1.381 \times 10^{-23} \mathrm{~J} \mathrm{~K}^{-1}\right), T$ is the 
Kelvin temperature, $z$ is the ionic charge, set to 1 in this paper, $e$ is the electron charge $\left(1.602 \times 10^{-19} \mathrm{C}\right), \sigma$ is the surface tension of water $\left(7.27 \times 10^{-2} \mathrm{~N} \mathrm{~m}^{-1}\right.$ at $\left.293 \mathrm{~K}\right), \lambda$ is the equivalent grain diameter $(\mathrm{m}), h_{r}$ is the matric suction $(\mathrm{m})$.

In this paper, only the drainage process is considered. Haines (1930) showed that $\rho g h_{r} \approx 26 \delta / \lambda$ in a mono-disperse close packing of spherical grains. Therefore, Eq. (7) can be rewritten as

$$
f_{r}=a\left(h_{r}\right)^{-0.5}
$$

where

$$
a=\sqrt{\frac{\varepsilon \varepsilon_{0}}{2}}\left(\frac{\pi k_{B} T}{z e}\right)\left(\frac{15 \rho g}{13}\right)^{-0.5}
$$

which gives $1.39 \times 10^{-8} \mathrm{~m}^{1.5}$.

To determine $K_{f}^{r}$ from Eq. (6), another step is to choose a proper value of $h_{m}$ so that $\theta_{m}$ and $f_{m}$ can be estimated. This matric suction should be large enough to avoid the impact of capillary forces, that is, the water is completely held by adsorption forces (validation of Eq. 5). Meanwhile, an upper limit of $h_{m}$ is required to it make sure that the film water can cover the entire area of the particle surface. Lebeau and Konrad (2010) simply set $h_{m}$ to $1.0 \times 10^{3} \mathrm{~m}$. Here, this critical value, $h_{m}$, is assumed to correspond to the suction where the particle surface is covered by a monolayer of water molecules. The film thickness, $f_{m}$, therefore, equals to about $3.5 \times 10^{-10} \mathrm{~m}$ (Hagymassy et al., 1969; Möhlmann, 2008; Leão and Tuller, 2014). At this very high matric suction, the van der Waals forces dominate (Tokunaga, 2011). The suction $h_{m}$ can be calculated from the film thickness equation that accounts for the van der Waals forces, written as (Iwamatsu and Horii, 1996) 


$$
h_{m}=\frac{-A_{s v l}}{6 \pi \rho g\left(f_{m}\right)^{3}}
$$

where $A_{s v l}$ is the Hamaker constant for solid-vapor interactions through the intervening liquid. This constant, $A_{s v l}$, lies within the typical value between $-10.0 \times 10^{-20} \mathrm{~J}$ and $-1.0 \times 10^{-20} \mathrm{~J}$ as reported in the literature (Tuller and Or, 2001, 2005; Resurreccion et al., 2011). Tuller and Or (2001) defined a value of $-6.0 \times 10^{-20} \mathrm{~J}$ as an effective Hamaker constant. Although widely accepted in the literature (e.g. Tuller and Or, 2005; Resurreccion et al., 2011; Arthur et al., 2013; Leão and Tuller, 2014) and also used in Lebeau and Konrad (2010), this effective value accounts for both van der Waals and ionic electrostatic forces as pointed out by Tokunage (2011). As discussed previously, the $h_{m}$ defined here is for conditions when the van der Waals forces dominate, thus a different value for $A_{s v l}$ should apply. Resurreccion et al., (2011) tested the Tuller and Or's model with 41 soils, showing that a typical value of $-1.0 \times 10^{-20} \mathrm{~J}$ for $A_{s v l}$ gives a better description of film thickness under monolayer water condition (Fig.3 in Resurreccion et al., 2011). In this paper, both the value of $-6.0 \times 10^{-20} \mathrm{~J}$ and $-1.0 \times 10^{-20} \mathrm{~J}$ are tested, resulting in the $h_{m}$ of $7.595 \times 10^{3} \mathrm{~m}$ and $1.265 \times 10^{3} \mathrm{~m}$, respectively. After determining $h_{m}$, the water content, $\theta_{m}$, is calculated from Eq. (1).

In summary, with the $K_{f}^{r}$ predicted by Eq. (6), the modified EMFX model now has the capacity to predict the hydraulic conductivity from the SWRC. To illustrate the difference, we refer to this modified model as the EMFX-K model. Here K means that the major improvement to the EMFX model is on estimating the saturated film conductivity. 


\subsection{Fitting the SWRC}

To predict the hydraulic conductivity, the parameters need to be defined by fitting the SWRC with observations. When Eq. (1) is applied to fit the water retention data, the model doesn't change sensitively with the value of $h_{r}$, which, however, is important in determining the conductivity function (see the sensitivity analysis in section 4.2.3). Practically, the value of $h_{r}$ needs to be defined in advance.

Campbell and Shiozawa (1992) showed that the water content below $\theta_{r}$ decreases linearly with the log-scale matric suction. Here, with the help of the air-entry suction $\left(h_{a}\right)$ and the residual water suction $\left(h_{r}\right)$, the complete SWRC is simply divided into three regimes, each represented by liner or log-scale liner relationship, then, the SWRC can be written as

$$
\theta= \begin{cases}\theta_{s} & h \leq h_{a} \\ \theta_{r}+\left(\theta_{s}-\theta_{r}\right) \frac{\ln \left(h / h_{r}\right)}{\ln \left(h_{a} / h_{r}\right)} & h_{a}<h<h_{r} \\ \theta_{r} \frac{\ln \left(h / h_{0}\right)}{\ln \left(h_{r} / h_{0}\right)} & h \geq h_{r}\end{cases}
$$

Eq. (11) performed well in finding the value of $h_{r}$ as shown in section 4 .

\subsection{In comparison with other soil hydraulic model}

To demonstrate the model performance, the commonly used van Genuchten (1980)-Mualem (1976a) model (hereafter the VG-M model) was introduced for comparison.

In the VG-M model, the SWRC is described as

$$
S_{c}=\frac{\theta-\theta_{r}}{\theta_{s}-\theta_{r}}=\left[1+(\alpha h)^{n}\right]^{-m}
$$


And with the assumption, $m=1-1 / n$, the hydraulic conductivity is expressed as

$$
K=K_{s} S_{c}^{0.5}\left[1-\left(1-S_{c}^{1 / m}\right)^{m}\right]^{2}
$$

The parameters in Eqs. (12) and (13) have the same meaning as that in the EMFX model.

\section{Model testing and demonstration}

\subsection{Data for testing}

Totally observations of 24 soils from literature and the UNSODA database (Nemes et al., 2001) were chosen for model testing. These data, with soil texture ranging from sand to clay, cover very dry conditions (Table 1). Data of 14 soils were the same as those used in Wang et al. (2016), while data of additional ten soils were selected from the UNSODA database.

\section{[Table 1 near here]}

\subsection{Testing procedure}

For the EMFX-K model, Eq. (11) was firstly fitted with the observations to define $h_{r}$, after this, the other parameters $(\alpha, n$ and $m)$ were determined by optimizing Eq. (1) with observed water retention data. The saturated film conductivity was calculated from Eq. (6), and then the hydraulic conductivity was predicted with Eq. (3). For the VG-M model, Eq. (12) was fitted with the observations to determine the parameters $\left(\alpha, n\right.$ and $\left.\theta_{r}\right)$, and the hydraulic conductivity was predicted with Eq. (13).

The optimization function was defined as 


$$
\Phi(b)=\sum_{i=1}^{n_{\theta}}\left[\theta_{i}-\theta_{i}(b)\right]^{2}
$$

where $n_{\theta}$ is the number of data pairs for the retention function, $\theta_{i}$ and $\theta_{i}$ are the measured and the model estimated water content, respectively, $b=\left(h_{r}, \alpha, n, m\right)$ is the parameter vector used for optimization. Note that as shown in Eq. (3), when $n$ is close to 1 , the capillary conductivity will be very close to zero. Therefore, a minimum value of 1.2 in the optimization is suggested for the parameter, $n$. Eq. (14) is minimized with the SCE-UA method proposed by Duan et al. (1992). This optimization method is also applied for the VG-M model.

To evaluate the model performance, the root mean squared errors, $\mathrm{RMSE}_{\theta}$ and $\mathrm{RMSE}_{\log K r}$, were introduced as

$$
\operatorname{RMSE}_{\theta}=\sqrt{\frac{1}{n_{\theta}} \sum_{i=1}^{n_{\theta}}\left(\theta_{i}-\theta_{i}\right)^{2}}
$$

and

$$
R M S E_{\log K r}=\sqrt{\frac{1}{n_{K}} \sum_{i=1}^{n_{K}}\left(\log _{10}\left(K_{i}\right)-\log _{10}\left(K_{i}\right)\right)^{2}}
$$

where $n_{K}$ is the number of data pairs for the hydraulic conductivity function, $K_{i}$ and $\widehat{K}_{i}$ are the measured and the model estimated conductivity, respectively

\section{Results and discussion}

\subsection{Model testing}

[Table 2 near here]

The fitted parameters of the SWRCs of the EMFX-K model and the VG-M model were presented in Table 2. 


\section{[Table 3 near here]}

Table 3 illustrates the statistical values for the 24 soils with the commonly used VG-M model and the EMFX-K model with $A_{s v l}$ equals $-6.0 \times 10^{-20} \mathrm{~J}$ and $-1.0 \times 10^{-20} \mathrm{~J}$, respectively. The average RMSE values for all 24 soils and the standard deviations are given in the last two rows of the table. It is clear that for most soils (17 out of 24), the EMFX-K model gives better performance in comparison with the VG-M model. The mean $\mathrm{RMSE}_{\log K r}$ predicted by the EMFX-K model (0.666) is about half of that of the VG-M model (1.495). When the EMFX-K models that with two different $A_{s v l}$ values are both in good agreement with the observations, for 20 out of all 24 soils, the model with $A_{s v l}$ of $-1.0 \times 10^{-20} \mathrm{~J}$ yields better performance than that with the commonly used value of $-6.0 \times 10^{-20} \mathrm{~J}$. The result is consistent with the notion that the value of $-6.0 \times 10^{-20} \mathrm{~J}$ suggested by Tuller and Or (2001) includes both impacts of the ionic electrostatic and van der Waals forces (Tokunage, 2011). The result also suggests that a value of $-1.0 \times 10^{-20} \mathrm{~J}$ for $A_{s v l}$ very likely be appropriate to represent solely the effect of the van der Waals forces for different soils. For all 24 soils, the predicted results with the EMFX-K model of two different $A_{s v l}$ values and the VG-M model are also shown in Figs. 1 to 4.

\section{[Figure 1 near here]}

For the six soils shown in Fig. 1, the relative hydraulic conductivity predicted with the EMFX-K model is in close agreement with the measurements, including both the wet and dry ranges. The transition from capillary dominated zone to film dominated range is well captured by the EMFX-K model. Under wet conditions, setting $l$ to 0.5 
in the EMFX-K model yields good capacity in predicting the hydraulic conductivity. The capillary-associated conductivity in the EMFX-K model shows better agreement with the measurements than the VG-M model, except for Sandy loam and Hupsel sand.

\section{[Figure 2 near here]}

As shown in Fig. 2, the hydraulic conductivity data of the first four soils were provided with water content data. Generally, the predicted conductivity by the EMFX-K model is in good agreement with the observations over the entire moisture range. For Masa loamy sand, Adelanto loam, Shonai sand and Berlin coarse sand 1, however, the EMFX-K model shows underestimation when the moisture is close to the residual water content. Eq. (3) shows that the capillary conductivity in the EMFX-K model would decrease sharply to zero when the water content is approaching $\theta_{r}$. In contrast, the capillary saturation (the effective saturation $S_{c}$ ) in the VG-M model is calculated as a function of matric suction (Eq.12), therefore, the conductivity function of the VG-M model changes smoothly for moisture close to $\theta_{r}$ and it is always higher than zero. From the view of model structure, when the water content is close to $\theta_{r}$, the smoothly changed conductivity function of the VG-M model make it better represent the observations (Fig. 2). This might explain the relatively poor performance of the EMFX-K model for Hupsel sand, Masa loamy sand and Berlin coarse sand 1, in comparison with the VG-M model. However, the conductivity function in the EMFX-K model shows much more flexibility for the $m$ and $n$ relationship, which is not fixed as that in the VG-M model. 


\section{[Figure 3 near here]}

The data presented in Figs. 3 and 4 were chosen from the UNSODA database. The data sets of Seelow clay 1 (2360) and Seelow clay 2 (2361) were presented in Schindler et al., (1985) while other ten soils were all published in Becher (1970). All soils cover a moisture range down to the matric suction of $1.5 \times 10^{2} \mathrm{~m}$. The soil texture includes sand, silt loam, silt and clay. The hydraulic data were all determined from the steady state flow experiments (Becher, 1970).

For these twelve soils, a relatively poor agreement with measurements is observed for both models. Under wet conditions, for Plumhof sand 2, Bordenan sand 1, Bordenan sand 2, Seelow clay 1 and Northen silt loam 2, the EMFX-K model, although performs better than the VG-M model, still underestimates the hydraulic conductivity value. For Northen silt, Northen silt loam 1 and Northen silt loam 3, the VG-M model is in good agreement with observations while the EMFX-K model overestimates the hydraulic conductivity in the middle water content range. Both the EMFX-K model and the VG-M model over-predict the conductivity for Seelow clay 2, Hollern clay 1 and Hollern clay 2 under wet conditions. In summary, under wet conditions, neither model performs well for all soils. Note that, for these soils with fine texture, the fitted $n$ values all reached the lower-bound value in the EMFX-K model. Practically, a value close to 1 for the parameter $n$, yields better agreement with the soil water retention data for soils with fine texture. For the conductivity function, however, when $n$ is close to 1 , the capillary conductivity will be very close to zero, according to Eq. (3). Therefore, a minimum value of 1.2 for $n$ was applied in the 
optimization. This might be the reason for the relatively poor performance of the EMFX-K model for soils with fine texture, in comparison with the VG-M model.

\section{[Figure 4 near here]}

Although the EMFX-K model well reflects the transition from the capillary zone to the film zone, it yields about one to two orders of magnitude underestimation for the hydraulic conductivity under dry conditions for almost all 12 soils, except for the Holly clay 1 . Detailed discussion is given in the next section.

\section{[Figure 5 near here]}

All the predicted relative conductivity data, with the EMFX-K model and the VG-M model, respectively, are presented in Fig. 5. It is clear that the VG-M model greatly underestimates the hydraulic conductivity under dry conditions while the EMFX-K model, which includes the impact from adsorption forces, significantly improves the performance. The EMFX-K model also shows a small improvement under wet conditions, which might be ascribed to the model flexibility resulted from the free $m$ and $n$ relationship.

\subsection{Underestimation of the conductivity for soils with fine texture}

Particularly for soils with fine texture, the EMFX-K model results in underestimation of the hydraulic conductivity under dry conditions as shown in Figs. 3 and 4. Two possibilities may lead to this underestimation. First, the measured conductivity data might be higher than the real values. Second, the proposed method underestimates the hydraulic properties (e.g., the saturated film conductivity) due to either the under-prediction of the soil properties (e.g., the film thickness or the 
specific perimeter) or the misrepresentation of physical processes in the model. Considerable uncertainties due to the measurement error or due to the predicted method exist in model evaluation.

\subsubsection{Uncertainty in the observations}

The difficulty in determining the hydraulic properties under dry conditions has long been recognized (e.g. Stolte et al., 1994). Under dry conditions, the matric suction often goes outside the range of tensiometers, therefore, to obtain the data that covers a broad moisture range, a combination of different methods is needed (Dane and Topp, 2002; Vereecken et al., 2010), which might introduce substantial inconsistencies in the data. Besides, the extremely slow water flow rate and then the long equilibrium time under dry conditions (Vereecken et al., 2010), also introduce uncertainty in collecting soil hydraulic data. As pointed out by Wösten et al. (2001), the measurement accuracy might be the single most important factor that could improve the prediction of soil hydraulic properties. However, there is still no standardized method that can be used to ascertain the measurement quality (Vereecken et al., 2010).

Considering almost all the data, against which the model underestimation occurred, were adopted from Becher (1970), the EMFX-K underestimation with the EMFX-K model might be (partly) associated with the possible overestimation in the measurements.

\subsubsection{Uncertainty in the model prediction}

The uncertainties lie in the prediction method due to the limited data or to the model structure can also explain the one to two orders of magnitude underestimation 
for the conductivity data.

\section{(1) Uncertainty in the specific surface area prediction}

The specific surface area is a key factor in determining the film conductivity. The estimation of the specific surface area with Eq. (5) depends highly on the water content value at $h_{m}\left(1.265 \times 10^{3} \mathrm{~m}\right)$. But the water retention data of the twelve soils only cover the suction range to $1.50 \times 10^{2} \mathrm{~m}$. Therefore, a large uncertainty lies in predicting the value of $\theta_{m}$, and then in predicting the specific surface area. In addition, when the Tuller and Or's method is trusted to be proper in predicting the specific surface area, the value of $A_{s v l}$ varies between soils (Resurreccion et al., 2011). However, a constant value of $-1.0 \times 10^{-20} \mathrm{~J}$ was applied for all soils in this study.

\section{( 2 ) Uncertainty in the film thickness prediction}

Uncertainty also exists in estimating the film thickness. Resurreccion et al. (2011) found that the film thickness of soils with a small Dexter number, defined by the clay faction divided by the organic carbon content (Dexter et al., 2008), would be much higher (from double to four times as shown in Fig. 3 in Resurreccion et al., 2011) than that predicted by the Tuller and Or's (2005) model. For matric suction closes to $1.0 \times 10^{2} \mathrm{~m}$, the film thickness model used here (Eq. 7) produce a similar value with that predicted by the Tuller and Or's model. Since the film conductivity is cubic of the

film thickness (Eq. 4), this underestimation of film thickness can yield one to two order of magnitude underestimation of hydraulic conductivity, close to the underestimation of conductivity as presented here.

\section{( 3 ) Uncertainty in the model structure}


Besides the uncertainty lies in the soil properties prediction, the underestimation or even the neglect of capillary conductivity may also introduce the underestimation of the conductivity under dry conditions. In the EMFX-K model, the capillary conductivity becomes zero when the matric suction is higher than the critical suction, $h_{r}$. This assumption may not hold for soils with fine texture. According to Hanies (1930), the critical matric suction for film flow to dominate is about $9.36 \times 10^{2} \mathrm{~m}$ for the grains with the diameter of $2.00 \times 10^{-6} \mathrm{~m}$ (the upper diameter limit for clay fraction). That is, the water held by the capillary force may still exist in very fine pores under the predicted high matric suction range. The pressure difference between the surface adsorbed water and capillary held water can maintain the capillary-form water flow in the very fine pores. This possible situation, however, is not well studied and thus, not reflected in the proposed EMFX-K model.

\subsubsection{Sensitivity analysis}

To quantify the impact of different sources of uncertainty, the Sobol's method (Sobol, 1990, 2001) is applied for the sensitivity analysis. The sensitivity of the parameters is quantified by two indices, the first-order sensitivity index $\left(S_{i}\right)$ and the total-order sensitivity index $\left(S_{t}\right)$. Here, $S_{i}$ represents the impact from an individual parameter while $S_{t}$ represents the main effect of the parameter and its interactions with the other parameters. Details of this method is described in Appendix, and can also be found in Sobol (1990, 2001) and in Zhang et al., (2017).

For the soil water retention model, five parameters were considered, including the four parameters of the EMFX-K model and the suction data input, defined as $h \_i n p u t$. 
For the conductivity model, to represent the uncertainties in model prediction, two extra parameters, the specific surface area, $A$, and the film thickness, $f_{r}$, were included. According to the analysis in section 4.2 .4 , the specific surface area, $A$, and the estimated film thickness, $f_{r}$, were set to range from one to five times of the values calculated from Eqs. (5) and (7), respectively. And, $\pm 15 \%$ variation of input suction data was applied to represent the uncertainty in the data. The calculated values for the soil water retention model and the conductivity model were presented in Tab. 4.

\section{[Table 4 near here]}

Clearly, for the soil water retention model, $m$ is the most important single parameter while $\alpha$ and $n$ are other two parameters that have a significant effect. The model output is not sensitive to parameters $h_{-}$input and $h_{r}$.

For conductivity, similarly, $m$ is the most important factor, contributing total $88.5 \%$ variations in the model output. Besides, $n, h_{r}$ and $f_{r}$ are all sensitive parameters, with the first-order sensitivity index value all higher than 1\% (see Appendix). The high sensitivity index value of $f_{r}$ indicates that the uncertainty in film thickness estimation has a significant impact on the prediction of hydraulic conductivity. The impact of $\alpha$ on the model output is mainly through its interaction with other parameters, with the total sensitivity index value of $2.4 \%$. The impact from $h \_$input and the specific surface area, $A$, is insignificant.

In summary, when the parameters $\alpha, n, m$ and $h_{r}$ can be determined by fitting the SWRC with observations (both Eqs. 1 and 11), the uncertainty existing in the film thickness estimation has an important impact on the prediction of the hydraulic 
conductivity. However, the uncertainties in conductivity observation and in model structure cannot be evaluated from the sensitivity analysis.

\section{Conclusions}

Including the adsorption forces into the commonly used capillary dominant soil water retention relationship has been recognized as a significant progress in the soil hydraulic model development (Durner et al., 2014). The difficulty in measuring the hydraulic conductivity, particularly under dry conditions, calls for methods of predicting hydraulic conductivity over the complete moisture range from the SWRC. Based on the recently proposed EMFX model, we presented a method for predicting the hydraulic conductivity over the complete moisture range. The free fitted parameter, $K_{f}^{r}$, in the EMFX model was predicted from the SWRC, with this modification, the hydraulic conductivity can be directly determined from the SWRC. In comparison with the commonly used VG-M model, the modified EMFX model (the EMFX-K model), which includes the impact from adsorption forces, significantly improves the prediction of the conductivity under dry conditions. Besides, the model testing results suggest that setting the tortuosity parameter $l$ as 0.5 as in Mualem (1976a) yields a good prediction of capillary conductivity for the tested soils, and that $-1.0 \times 10^{-20} \mathrm{~J}$ might be a proper value for $A_{s v l}$ to represent solely the impact of the van der Waals forces for different soils.

Although the great improvement in predicting the hydraulic conductivity, the uncertainty from the data measurements and in some assumed values in the predicted 
method limit the evaluation and further improvement of the predicted method. The sensitivity analysis result shows that the uncertainty existing in film thickness estimation has an important impact on the prediction of the hydraulic conductivity, besides the parameters determined by fitting the SWRC. More data with high measurement quality under dry conditions for soils over a wide texture range are required to improve our understanding of the possible mechanism in supporting soil moisture movement under different moisture conditions, and to improve our ability in predicting the soil hydraulic properties.

From the viewpoint of the model structure, how to better represent the capillary conductivity near the residual water content and how to better estimate the matric suction at the residual saturation are the next steps to improve the performance of the EMFX-K model.

\section{Appendix}

The Sobol's method (Sobol, 1990, 2001) is a popular global sensitivity analysis based on variance decomposition. The model is represented in the following functional form:

$$
y=f(X, \vec{\theta})
$$

where $y$ is the model output; $X$ is the input variable; and $\vec{\theta}$ is the parameter vector. The total variance of function $D(y)$ can be decomposed into summands of increasing dimensionality, which can be expressed as: 


$$
D(y)=\sum_{i=1}^{k} D_{i}+\sum_{i=1}^{k-1} \sum_{j=i+1}^{k} D_{i j}+\cdots+D_{1, \ldots, k}
$$

where $D_{i}$ is the partial variance with the first-order index of $\theta_{i}$ on the model output $y$; $D_{i j}$ is the partial variance with the second-order index of the $i^{\text {th }}$ and $j^{\text {th }}$ parameter interactions; $k$ is the total number of parameters.

The sensitivity effect is characterized by the ratio of the partial variances to the total variance:

First-order index

$$
S_{i}=\frac{D_{i}}{D}
$$

Second-order index

$$
S_{i j}=\frac{D_{i j}}{D}
$$

Total-order index

$$
S_{t i}=S_{i}+\sum_{j \neq i} S_{i j}+\cdots=1-\frac{D_{\sim i}}{D}
$$

where $S_{i}$ is a measure ratio from the main effect of the individual parameter $\theta_{i}$ to the total model variance $D ; S_{i j}$ is the sensitivity that results from the interactions between $\theta_{i}$ and $\theta_{j}$; and $S_{t i}$ accounts for the main effect of $\theta_{i}$ and its interactions with the other parameters.

The Latin hypercube sampling (McKay, 1988) is used to sample the available parameter space. And 5,000 independent samples of the parameters are constructed for the evaluation.

Two threshold values following Tang et al. (2007) were introduced to demonstrate the parameter sensitivity. The highly sensitive parameters represented at least $10 \%$ 
contribution of the overall model output variance, and the sensitive parameters should contribute at least $1 \%$ of the overall model output variance, while the contributions were less than $1 \%$, the parameters were regarded as non-sensitive.

\section{Notation}

$a$ The combination factor in film thickness equation.

$A$ The specific surface area per unit volume of the porous media $\left(\mathrm{L}^{-2} \mathrm{~L}^{-3}\right)$.

$A_{s v l}$ The Hamaker constant for solid-vapor interactions through the intervening liquid $(\mathrm{J})$.

$b$ The parameter vector used for optimization.

$\alpha$ Fitted parameter $\left(\mathrm{L}^{-1}\right)$.

$c$ Scaling factor $(=0.01)$.

$D$ The total model variance.

$e$ The Euler's number (the $e$ constant).

$e_{i}$ The electron charge $\left(1.602 \times 10^{-19} \mathrm{C}\right)$

$\varepsilon$ The relative permittivity of water (78.54).

$\varepsilon_{0}$ The permittivity of free space $\left(8.85 \times 10^{-12} \mathrm{C}^{2} \mathrm{~J}^{-1} \mathrm{~m}^{-1}\right)$

$f$ Film thickness (L).

$f_{r}$ Film thickness at $S_{r}(\mathrm{~L})$.

$f_{m}$ Film thickness at $h_{m}(\mathrm{~L})$.

$\Gamma(h)$ Correction function in the EMFX model.

$\Phi(b)$ Objective function for optimization. 
$g$ The acceleration due to gravity $\left(\mathrm{L} \mathrm{T}^{-2}\right)$

$\theta$ Volumetric water content $\left(\mathrm{L}^{3} \mathrm{~L}^{-3}\right)$.

$\theta_{r}$ Residual water content $\left(\mathrm{L}^{3} \mathrm{~L}^{-3}\right)$.

$\theta_{s}$ Saturated water content $\left(\mathrm{L}^{3} \mathrm{~L}^{-3}\right)$.

$\theta_{i}$ Model estimated water content $\left(\mathrm{L}^{3} \mathrm{~L}^{-3}\right)$

$h$ Matric suction (L).

$h \_i n p u t$ The input suction data.

$h_{r}$ Matric suction corresponding to the residual water content (L).

$h_{m}$ A specific matric suction corresponding to monolayer water monocular (L).

$h_{0}$ Matric suction where water content is zero (L).

$K$ The total hydraulic conductivity $\left(\mathrm{L} \mathrm{T}^{-1}\right)$.

$k_{\mathrm{B}}$ The Boltzmann constant $\left(1.381 \times 10^{-23} \mathrm{~J} \mathrm{~K}^{-1}\right)$

$K_{f}^{r}$ Film conductivity at $S_{r}\left(\mathrm{~L} \mathrm{~T}^{-1}\right)$.

$K_{i}$ Model estimated conductivity values $\left(\mathrm{L} \mathrm{T}^{-1}\right)$.

$K_{r}$ Relative hydraulic conductivity.

$K_{s}$ Saturated hydraulic conductivity $\left(\mathrm{L} \mathrm{T}^{-1}\right)$.

$l$ Capillary model parameter.

$\lambda$ Grain diameter $(\mathrm{L})$.

$m$ Fitted parameter.

$n$ Fitted parameter.

$n_{K}$ The number of observed conductivity data

$n_{\theta}$ The number of retention data used for optimization. 
$P$ The specific grain perimeter length per unit cross-sectional area $\left(\mathrm{L} \mathrm{L}^{-2}\right)$

$\eta$ Viscosity of the fluid $\left(\mathrm{M} \mathrm{L}^{-1} \mathrm{~T}^{-1}\right)$.

$\rho$ Density of the fluid $\left(\mathrm{M} \mathrm{L}^{-3}\right)$.

$\mathrm{RMSE}_{\theta}$ Root mean squared error for water content.

$\mathrm{RMSE}_{\log K r}$ Root mean squared error for log-scale relative hydraulic conductivity.

$S$ Saturation degree.

$S_{c}$ The effective saturation where the capillary force dominates.

$S_{r}$ The saturation degree at the residual water content.

$S_{i}$ The first-order sensitivity index.

$S_{t}$ The total-order sensitivity index. $T$ The Kelvin temperature (K)

$\delta$ Surface tension $\left(\left(7.27 \times 10^{-2} \mathrm{~N} \mathrm{~m}^{-1}\right.\right.$ at $\left.\left.293 \mathrm{~K}\right)\right)$.

$z$ The ionic charge (1)

SWRC Soil water retention curve.

EMFX model The model proposed by Wang et al., (2016), as an extension and modification of the Fredlund and Xing's (1994) model.

EMFX-K model The modified EMFX model with saturated film conductivity predicted from the SWRC.

$V G-M$ model The model developed by van Genucthen (1980).

\section{Acknowledgments}

The research was supported by the National Science Foundation of China (Nos. 41601030 and U1403282)and by the Fundamental Research Funds for Central 
Universities, China University of Geosciences (Wuhan) (No. G1323521674). We wish to thank Marc Lebeau (Laval University, Quebec City, Canada), who kindly provided the data for soils 1 to 10 . We also wish to thank Kun Zhang (Lanzhou University, China) for his help in sensitivity analysis. Finally, the authors thank all anonymous reviewers for their very insightful and constructive comments on this manuscript.

\section{References}

Arthur, E., Tuller, M., Moldrup, P., Resurreccion, A. C., Meding, M. S., Kawamoto, K., ... \& De Jonge, L. W. (2013). Soil specific surface area and non-singularity of soil-water retention at low saturations. Soil Science Society of America Journal, 77(1), 43-53.

Becher, H. H. (1970). Eine Methode zur Messung der Wasserleitfähigkeit von Böden im ungesättigten Zustand. Technischen Universität, Fakultät für Gartenbau und Landeskultur.

Bird, R. B., Stewart, W. E., \& Lightfoot, E. N. (1960). Transport Phenomena, John Wiley, New York.

Campbell, G. S., \& Shiozawa, S. (1992). Prediction of hydraulic properties of soils using particle-size distribution and bulk density data. Indirect methods for estimating the hydraulic properties of unsaturated soils. University of California, Riverside, 317-328, Univ. of California, Riverside, CA, USA. 
Dane, J.H., \& Topp, G.C. (ed.). (2002). Methods of soil analysis. Part 4. Physical methods. SSSA Book Ser. 5. SSSA, Madison, WI.

Dexter, A. R., Richard, G., Arrouays, D., Czyż, E. A., Jolivet, C., \& Duval, O. (2008). Complexed organic matter controls soil physical properties. Geoderma, 144(3), 620-627.

Duan, Q., Sorooshian, S., \& Gupta, V. (1992). Effective and efficient global optimization for conceptual rainfall- runoff models. Water resources research, 28(4), 1015-1031, doi: 10.1029/91WR02985.

Durner, W., Diamantopoulos, E., Iden, S. C., \& Scharnagl, B. (2014), Hydraulic properties and non-equilibrium water flow in soils. In Application of Soil Physics in Environmental Analyses (pp. 403-434). Springer International Publishing.

Fujimaki, H., \& Inoue, M. (2003a). A transient evaporation method for determining soil hydraulic properties at low pressure, Vadose Zone Journal., 2(3), 400 - 408, doi:10.2113/2.3.400.

Fujimaki, H., \& Inoue, M. (2003b). A flux-controlled steady-state evaporation method for determining unsaturated hydraulic conductivity at low matric pressure head values. Soil science, 168(6), 385-395, doi:10.1097/ 00010694-200306000-00001.

Fredlund, D. G., \& Xing, A. (1994). Equations for the soil-water characteristic curve. Canadian geotechnical journal, 31(4), 521-532, doi: 10.1139/t94-061.

Hagymassy, J., Brunauer, S., \& Mikhail, R. S. (1969). Pore structure analysis by water vapor adsorption: I. t-Curves for water vapor. Journal of Colloid and Interface Science, 29(3), 485-491. 
Haines, W. B. (1930), Studies in the physical properties of soil. V. The hysteresis effect in capillary properties, and the modes of moisture distribution associated therewith, The Journal of Agricultural Science, 20(01), 97 - 116, doi:10.1017/S002185960008864X.

Hillel, D. (1982). Introduction to soil physics, Academic press, New York.

Iwamatsu, M., \& Horii, K. (1996). Capillary condensation and adhesion of two wetter surfaces. Journal of colloid and interface science, 182(2), 400-406.

Jensen, D. K., Tuller, M., de Jonge, L. W., Arthur, E., \& Moldrup, P. (2015). A New Two-Stage Approach to predicting the soil water characteristic from saturation to oven-dryness. Journal of Hydrology, 521, 498-507.

Leão, T. P., \& Tuller, M. (2014). Relating soil specific surface area, water film thickness, and water vapor adsorption. Water Resources Research,50(10), 7873-7885.

Lebeau, M., \& Konrad, J. M. (2010). A new capillary and thin film flow model for predicting the hydraulic conductivity of unsaturated porous media. Water Resources Research, 46(12)., doi:10.1029/2010WR009092.

Lenormand, R. (1990), Liquids in porous media, Journal of Physics: Condensed Matter, 2, SA79-SA88, doi:10.1088/0953-8984/2/S/008.

Yu, L., \& Wardlaw, N. C. (1986). Mechanisms of nonwetting phase trapping during imbibition at slow rates. Journal of colloid and interface science,109(2), 473-486., doi:10.1016/0021-9797(86)90325-5. 
McKay, M. D. (1988). Sensitivity and uncertainty analysis using a statistical sample of input values. Uncertainty analysis, 145-186.

Mehta, B. K., Shiozawa, S. H. O., \& Nakano, M. (1994). Hydraulic properties of a sandy soil at low water contents. Soil science, 157(4), 208-214., doi:10.1097/00010694-199404000-00002.

Möhlmann, D. T. (2008). The influence of van der Waals forces on the state of water in the shallow subsurface of Mars. Icarus, 195(1), 131-139.

Mualem, Y. (1976). A new model for predicting the hydraulic conductivity of unsaturated porous media. Water resources research,12(3), 513-522., doi:10.1029/WR012i003p00513.

Mualem, Y. (1976b). A Catalogue of the Hydraulic Properties of Unsaturated Soils, 100 pp., Technion, Israel Inst. of Technol., Haifa, Israel.

Nemes, A., Schaap, M. G., Leij, F. J., \& Wösten, J. H. M. (2001). Description of the unsaturated soil hydraulic database UNSODA version 2.0. Journal of Hydrology, 251(3), 151-162., doi:10.1016/S0022-1694(01)00465-6.

Or, D., \& Tuller, M. (1999). Liquid retention and interfacial area in variably saturated porous media: Upscaling from single- pore to sample- scale model. Water Resources Research, 35(12), 3591-3605, doi:10.1029/1999WR900262.

Pachepsky, Y. A., Shcherbakov, R. A., Varallyay, G., \& Rajkai, K. (1984). On obtaining soil hydraulic conductivity curves from water retention curves (in Russian), Pochvovedenie, 10, $60-72$. 
Pachepsky, Y., \& Rawls, W. J. (Eds.). (2004). Development of pedotransfer functions in soil hydrology (Vol. 30). Elsevier, Amsterdam.

Peters, A. (2013). Simple consistent models for water retention and hydraulic conductivity in the complete moisture range. Water Resources Research,49(10), 6765-6780., doi:10.1002/wrcr.20548.

Resurreccion, A. C., Moldrup, P., Tuller, M., Ferré, T. P. A., Kawamoto, K., Komatsu, T., \& De Jonge, L. W. (2011). Relationship between specific surface area and the dry end of the water retention curve for soils with varying clay and organic carbon contents. Water Resources Research, 47(6).

Schaap, M. G., \& Van Genuchten, M. T. (2006). A modified Mualem-van Genuchten formulation for improved description of the hydraulic conductivity near saturation. Vadose Zone Journal, 5(1), 27-34.

Schindler, U., Bohne, K., \& Sauerbrey, R. (1985). Comparison of different measuring and calculating methods to quantify the hydraulic conductivity of unsaturated soil.Zeitschrift für Pflanzenernährung und Bodenkunde, 148(6), 607-617, doi: 10.1002/jpln.19851480603.

Schneider, M., \& Goss, K. U. (2012). Prediction of the water sorption isotherm in air dry soils. Geoderma, 170, 64-69, doi:10.1016/j.geoderma.2011.10.008.

Stolte, J., Halbertsma, J. M., Veerman, G. J., Wösten, J. H. M., Freijer, J. I., Bouten, W., ... \& Van den Berg, J. A. (1994). Comparison of six methods to determine unsaturated soil hydraulic conductivity. Soil Science Society of America Journal, 58(6), 1596 - 1603, doi:10.2136/sssaj1994.03615995005800060002x. 
Silva, O., \& Grifoll, J. (2007). A soil- water retention function that includes the hyper- dry region through the BET adsorption isotherm. Water resources research, 43(11), doi:10.1029/2006WR005325.

Sobol, I. M. (1990), On sensitivity estimation of nonlinear mathematical models, Matem. Mod., 2(1), 112-118.

Sobol, I. M. (2001). Global sensitivity indices for nonlinear mathematical models and their Monte Carlo estimates. Mathematics and computers in simulation, 55(1), 271-280. Tang, T., Reed, P., Wagener, T., \& Van Werkhoven, K (2007). Comparing sensitivity analysis methods to advance lumped watershed model identification and evaluation, Hydrology and Earth System Sciences, 11(2), 793-817.

Toledo, P. G., Novy, R. A., Davis, H. T., \& Scriven, L. E. (1990). Hydraulic conductivity of porous media at low water content. Soil Science Society of America Journal, 54(3), 673-679, doi:10.2136/sssaj1990.03615995005400030007x.

Tokunaga, T. K. (2009). Hydraulic properties of adsorbed water films in unsaturated porous media. Water resources research, 45(6), doi:10.1029/2009WR007734.

Tokunaga, T. K. (2011). Physicochemical controls on adsorbed water film thickness in unsaturated geological media. Water Resources Research,47(8), doi:10.1029/2011WR010676.

Tuller, M., Or, D., \& Dudley, L. M. (1999). Adsorption and capillary condensation in porous media: Liquid retention and interfacial configurations in angular pores. Water Resources Research, 35(7), 1949-1964. 
Tuller, M., \& Or, D. (2001). Hydraulic conductivity of variably saturated porous media: Film and corner flow in angular pore space. Water Resources Research, 37(5), 1257-1276, doi:10.1029/2000WR900328.

Tuller, M., \& Or, D. (2005). Water films and scaling of soil characteristic curves at low water contents. Water Resources Research, 41(9).

Van Genuchten, M. T. (1980). A closed-form equation for predicting the hydraulic conductivity of unsaturated soils. Soil science society of America journal, 44(5), 892-898, doi:10.2136/sssaj1980.03615995004400050002x.

Vereecken, H., Weynants, M., Javaux, M., Pachepsky, Y., Schaap, M. G., \& Genuchten, M. T. (2010). Using pedotransfer functions to estimate the van Genuchten-Mualem soil hydraulic properties: a review. Vadose Zone Journal,9(4), 795-820.

Wang, Y., Ma, J., Zhang, Y., Zhao, M., \& Edmunds, W. M. (2013). A new theoretical model accounting for film flow in unsaturated porous media.Water Resources Research, 49(8), 5021-5028, doi:10.1002/wrcr.20390.

Wang, Y., Ma, J., \& Guan, H. (2016). A mathematically continuous model for describing the hydraulic properties of unsaturated porous media over the entire range of matric suctions. Journal of Hydrology, 541, 873-888.

Weynants, M., Vereecken, H., \& Javaux, M. (2009). Revisiting Vereecken pedotransfer functions: Introducing a closed-form hydraulic model. Vadose Zone Journal, 8(1), 86-95. 
Wösten, J. H. M., Pachepsky, Y. A., \& Rawls, W. J. (2001). Pedotransfer functions: bridging the gap between available basic soil data and missing soil hydraulic characteristics. Journal of Hydrology, 251(3), 123-150.

Zhang, K., Ma, J., Zhu, G., Ma, T., Han, T., \& Feng, L. L. (2017). Parameter sensitivity analysis and optimization for a satellite- based evapotranspiration model across multiple sites using Moderate Resolution Imaging Spectroradiometer and flux data. Journal of Geophysical Research: Atmospheres, 122, 230-245, doi:10.1002/2016JD025768.

Zhang, Z. F. (2011). Soil water retention and relative permeability for conditions from oven-dry to full saturation. Vadose Zone Journal,10(4), 1299-1308, doi:10.2136/vzj2011.0019.

\section{Figure Captions}

Figure 1. Model predicted relative hydraulic conductivity for soils 1 to 6 ( $K_{o}$ and $K_{p}$ are the observed and predicted relative conductivity, respectively)

Figure 2. Model predicted relative hydraulic conductivity for soils 7 to 12

Figure 3. Model predicted relative hydraulic conductivity for soils 13 to 18

Figure 4. Model predicted relative hydraulic conductivity for soils 19 to 24

Figure 5. Predicted relative hydraulic conductivity vs. the observation for all soils, from the EMFX-K model and the VG-M model, respectively (the data set of Shonai sand was removed in $\mathrm{c}$ and $\mathrm{d})$. 


\section{Table Captions}

Table 1. Soil properties of the testing data (Fourteen data sets are also included in Wang et al. 2016 while additional ten data sets are selected from the UNSODA database)

Tabel 2. Optimized parameters for the SWRC of the EMFX-K model and the VG-M model

Table 3. The statistics showing the model performance ${ }^{a}$

Table 4. The first-order and total sensitivity indices of the parameters in predicting $\theta$ and $K$, respectively. 
Table 1. Soil properties of the testing data (Fourteen data sets are also included in Wang et al. 2016 while additional ten data sets are selected from the UNSODA database)

\begin{tabular}{|c|c|c|c|c|}
\hline No & Data Set & Reference $^{\mathrm{a}}$ & $\theta_{s}$ & $K_{s}(\mathrm{~cm} / \mathrm{d})^{\mathrm{b}}$ \\
\hline 1 & Sandy loam & A & 0.43 & 8.00 \\
\hline 2 & Shonai sand & B & 0.43 & 941.76 \\
\hline 3 & Masa loamy sand & $\mathrm{C}$ & 0.34 & 50.98 \\
\hline 4 & Gilat loam & $\mathrm{D}$ & 0.44 & 17.28 \\
\hline 5 & Pachapa loam & $\mathrm{D}$ & 0.46 & 17.28 \\
\hline 6 & Adelanto loam & $\mathrm{D}$ & 0.43 & 3.89 \\
\hline 7 & Pachapa fine sany clay & $\mathrm{D}$ & 0.33 & 12.10 \\
\hline 8 & Rehovot sand & $\mathrm{D}$ & 0.40 & 1100.0 \\
\hline 9 & Berlin medium sand 4 & $\mathrm{E}$ & 0.39 & 692.06 \\
\hline 10 & Hupsel sand & $\mathrm{E}$ & 0.36 & 705.02 \\
\hline 11 & Berlin coarse sand 1( 1460$)$ & $\mathrm{E}$ & 0.261 & 251.00 \\
\hline 12 & Berlin coarse sand 2( 1461$)$ & $\mathrm{E}$ & 0.362 & 2000.00 \\
\hline 13 & Seelow clay 1 ( 2360 ) & $\mathrm{F}$ & 0.49 & 5.00 \\
\hline 14 & Seelow clay 2 ( 2361$)$ & $\mathrm{F}$ & 0.557 & 2.00 \\
\hline 15 & Plumhof sand $1 \quad(4650)$ & $\mathrm{G}$ & 0.38 & 586.70 \\
\hline 16 & Plumhof sand 2 (4651) & $\mathrm{G}$ & 0.377 & 190.10 \\
\hline 17 & Bordenan sand 1 ( 4660$)$ & G & 0.463 & 625.50 \\
\hline 18 & Bordenan sand 2 ( 4661$)$ & $\mathrm{G}$ & 0.428 & 1140.00 \\
\hline
\end{tabular}




$\begin{array}{lllll}19 & \text { Northen silt (4670) } & \text { G } & 0.463 & 88.99 \\ 20 & \text { Northen silt loam 1 (4671) } & \text { G } & 0.412 & 12.27 \\ 21 & \text { Northen silt loam 2 (4672) } & \text { G } & 0.394 & 2.42 \\ 22 & \text { Northen silt loam3 (4673) } & \text { G } & 0.415 & 4.33 \\ 23 & \text { Hollern clay 1 ( 4680) } & \text { G } & 0.555 & 20.00 \\ 24 & \text { Hollern clay 2 }(4681) & \text { G } & 0.578 & 10.00\end{array}$

${ }^{a}$ A, Pachepsky et al. (1984); B, Mehta et al. (1994); C, Fujimaki and Inoue (2003a, 2003b); D, Mualem (1976b); E, Nemes et al. (2001); F, Schindler et al., (1985); G, Becher, (1970). ${ }^{\text {b For }}$ soils 15 and 16, the saturated conductivity data are fitted using the EMFX model.

Tabel 2. Optimized parameters for the SWRC of the EMFX-K model and the VG-M model

\begin{tabular}{|c|c|c|c|c|c|c|c|}
\hline \multirow[t]{2}{*}{ Data Set } & \multicolumn{4}{|c|}{ EMFX-K } & \multicolumn{3}{|c|}{ VG-M } \\
\hline & $\alpha(1 / \mathrm{cm})$ & $h_{r}(\mathrm{~cm})$ & $m$ & $n$ & $\alpha(1 / \mathrm{cm})$ & $\theta_{r}$ & $n$ \\
\hline Sandy loam & 0.008 & 1724 & 1.30 & 1.20 & 0.011 & 0.05 & 1.72 \\
\hline Gilat loam & 0.022 & 154 & 0.54 & 4.33 & 0.017 & 0.08 & 2.44 \\
\hline Rehovot sand & 0.048 & 68 & 1.33 & 3.64 & 0.045 & 0.01 & 3.13 \\
\hline Pachapa fine sandy clay & 0.014 & 299 & 0.92 & 5.56 & 0.011 & 0.06 & 2.10 \\
\hline
\end{tabular}




\begin{tabular}{|c|c|c|c|c|c|c|c|}
\hline Berlin medium sand 4 & 0.032 & 66 & 0.80 & 9.00 & 0.029 & 0.03 & 4.38 \\
\hline Hupsel sand & 0.045 & 68 & 0.92 & 5.56 & 0.034 & 0.03 & 3.92 \\
\hline Masa loamy sand & 0.016 & 579 & 0.98 & 1.44 & 0.015 & $0.00^{\mathrm{a}}$ & 1.55 \\
\hline Adelanto loam & 0.004 & 962 & 0.46 & 2.44 & 0.006 & $0.00^{\mathrm{a}}$ & 1.27 \\
\hline Pachapa loam & 0.008 & 743 & 0.79 & 2.43 & 0.007 & 0.03 & 1.84 \\
\hline Shonai sand & 0.050 & 42 & 0.73 & 8.86 & 0.041 & $0.01^{\mathrm{a}}$ & 3.66 \\
\hline Berlin coarse sand 1 ( 1460$)$ & 0.033 & 96 & 0.80 & 5.15 & 0.028 & 0.02 & 0.028 \\
\hline Berlin coarse sand $2(1461)$ & 0.065 & 65 & 0.86 & 9.00 & 0.071 & 0.02 & 3.00 \\
\hline Seelow clay 1 ( 2360$)$ & 0.011 & 10018 & 0.21 & 1.20 & 0.017 & 0.10 & 1.10 \\
\hline Seelow clay 2 ( 2361$)$ & 0.001 & 9280 & 0.23 & 1.20 & 0.001 & 0.34 & 1.36 \\
\hline Plumhof sand 1 ( 4650$)$ & 0.050 & 86 & 0.90 & 3.06 & 0.044 & 0.03 & 2.20 \\
\hline Plumhof sand 2 (4651) & 0.074 & 115 & 0.84 & 1.93 & 0.060 & 0.06 & 1.98 \\
\hline Bordenan sand 1 ( 4660$)$ & 0.146 & 269 & 0.93 & 1.20 & 0.228 & 0.04 & 1.41 \\
\hline Bordenan sand 2 ( 4661$)$ & 0.110 & 112 & 1.17 & 1.42 & 0.128 & 0.03 & 1.72 \\
\hline Northen silt (4670) & 0.004 & 4622 & 1.04 & 1.20 & 0.008 & 0.02 & 1.40 \\
\hline Northen silt loam 1 (4671) & 0.003 & 5862 & 0.93 & 1.20 & 0.005 & 0.00 & 1.34 \\
\hline Northen silt loam 2 (4672) & 0.005 & 10037 & 0.40 & 1.20 & 0.008 & 0.07 & 1.19 \\
\hline Northen silt loam3 (4673) & 0.002 & 4921 & 0.79 & 1.20 & 0.005 & 0.04 & 1.30 \\
\hline Hollern clay 1 ( 4680$)$ & 0.005 & 584 & 0.29 & 1.20 & 0.008 & 0.00 & 1.12 \\
\hline Hollern clay 2 ( 4681$)$ & 0.002 & 3359 & 0.30 & 1.20 & 0.005 & 0.35 & 1.34 \\
\hline
\end{tabular}

${ }^{\mathrm{a}}$ To prevent negative values, the residual water content is fixed to or close to zero. 
Table 3. The statistics showing the model performance ${ }^{a}$

\begin{tabular}{|c|c|c|c|c|c|}
\hline \multirow[t]{3}{*}{ Data Set } & \multicolumn{3}{|c|}{ EMFX-K } & \multicolumn{2}{|c|}{ VG-M } \\
\hline & $\operatorname{RMSE}_{\theta}$ & $\mathrm{RMSE}_{\log K r}$ & $\mathrm{RMSE}_{\log K r}$ & $\operatorname{RMSE}_{\theta}$ & $\mathrm{RMSE}_{\log K r}$ \\
\hline & & $\left(-6.0 \times 10^{-20}\right)$ & $\left(-1.0 \times 10^{-20}\right)$ & & \\
\hline Sandy loam & 0.007 & 0.587 & 0.463 & 0.018 & 2.216 \\
\hline Gilat loam & 0.004 & 0.337 & 0.193 & 0.017 & 3.850 \\
\hline Rehovot sand & 0.003 & 0.388 & 0.302 & 0.006 & 1.010 \\
\hline Pachapa fine sandy clay & 0.007 & 0.561 & 0.416 & 0.009 & 1.264 \\
\hline Berlin medium sand 4 & 0.005 & 0.577 & 0.365 & 0.012 & 1.486 \\
\hline Hupsel sand & 0.007 & 1.737 & 1.620 & 0.006 & 0.962 \\
\hline Masa loamy sand & 0.004 & 0.717 & 0.546 & 0.018 & 0.336 \\
\hline Adelanto loam & 0.008 & 0.798 & 0.611 & 0.017 & 1.200 \\
\hline Pachapa loam & 0.008 & 0.210 & 0.292 & 0.016 & 2.318 \\
\hline Shonai sand & 0.015 & 1.200 & 1.274 & 0.025 & 3.154 \\
\hline Berlin coarse sand $1(1460)$ & 0.004 & 1.039 & 0.853 & 0.012 & 0.748 \\
\hline Berlin coarse sand $2(1461)$ & 0.002 & 0.394 & 0.392 & 0.004 & 0.947 \\
\hline Seelow clay 1 ( 2360$)$ & 0.007 & 0.788 & 0.736 & 0.004 & 2.353 \\
\hline Seelow clay 2 ( 2361 ) & 0.004 & 0.620 & 0.580 & 0.005 & 0.620 \\
\hline
\end{tabular}




\begin{tabular}{|c|c|c|c|c|c|}
\hline Plumhof sand 1 ( 4650$)$ & 0.006 & 0.940 & 0.718 & 0.011 & 2.434 \\
\hline Plumhof sand 2 (4651) & 0.015 & 0.812 & 0.649 & 0.011 & 2.426 \\
\hline Bordenan sand 1 ( 4660$)$ & 0.014 & 0.972 & 0.817 & 0.015 & 2.290 \\
\hline Bordenan sand 2 ( 4661$)$ & 0.010 & 1.040 & 0.827 & 0.010 & 2.378 \\
\hline Northen silt (4670) & 0.023 & 0.759 & 0.686 & 0.023 & 0.380 \\
\hline Northen silt loam 1 (4671) & 0.016 & 0.561 & 0.485 & 0.017 & 0.444 \\
\hline Northen silt loam 2 (4672) & 0.007 & 0.616 & 0.581 & 0.005 & 1.256 \\
\hline Northen silt loam3 (4673) & 0.012 & 0.590 & 0.509 & 0.017 & 0.648 \\
\hline Hollern clay 1 ( 4680$)$ & 0.006 & 0.801 & 0.876 & 0.004 & 0.764 \\
\hline Hollern clay 2 ( 4681$)$ & 0.010 & 1.229 & 1.204 & 0.016 & 1.111 \\
\hline mean & 0.009 & 0.761 & 0.666 & 0.012 & 1.495 \\
\hline sd. & 0.005 & 0.328 & 0.327 & 0.006 & 0.940 \\
\hline
\end{tabular}

${ }^{\mathrm{a}}$ The lowest value is highlighted in bond

Table 4. The first-order and total sensitivity indices of the parameters in predicting $\theta$ and $K$, respectively.

\begin{tabular}{ccccc|ccccc}
\hline$\theta$ & Parameter & $S_{i}$ & Parameter & $S_{t}$ & $K$ & Parameter & $S_{i}$ & Parameter & $S_{t}$ \\
\hline$m$ & 0.902 & $m$ & 0.913 & & $m$ & 0.788 & $m$ & 0.885 \\
$\alpha$ & 0.099 & $\alpha$ & 0.115 & & $n$ & 0.095 & $n$ & 0.134
\end{tabular}




\begin{tabular}{|c|c|c|c|c|c|c|c|}
\hline$n$ & 0.032 & $n$ & 0.036 & $h_{r}$ & 0.016 & $f_{r}$ & 0.065 \\
\hline$h \_$input & $0.000^{\mathrm{a}}$ & $h \_$input & 0.001 & $f_{r}$ & 0.011 & $h_{r}$ & 0.040 \\
\hline \multirow[t]{3}{*}{$h_{r}$} & $0.000^{\mathrm{a}}$ & $h_{r}$ & 0.001 & $\alpha$ & 0.007 & $\alpha$ & 0.024 \\
\hline & & & & $A$ & 0.005 & $A$ & 0.008 \\
\hline & & & & $h \_$input & 0.001 & h_input & 0.001 \\
\hline
\end{tabular}

${ }^{\text {a }}$ The value of $S_{i}$ was slightly smaller than 0 because of numerical integration. The value was therefore reset to 0 . 
Sandy loam

$\left(\lg K_{p}=0.9 \lg K_{o}-0.85, K^{2}=0.99, n=26\right)$

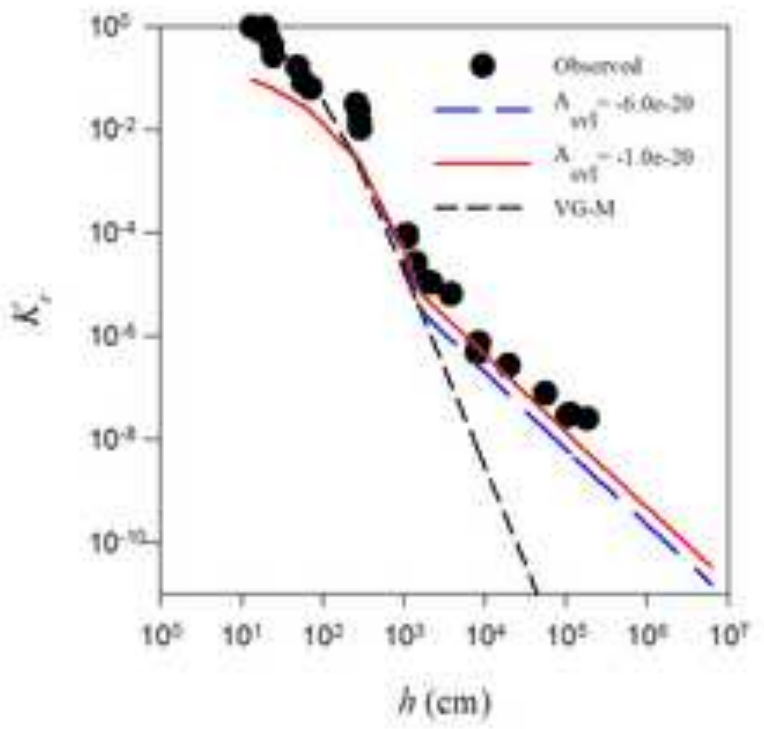

Pachapa fine sandy clay

$\left(\lg K_{p}=1.00 \lg K_{o}-0.28, R^{2}=0.99, n=23\right)$

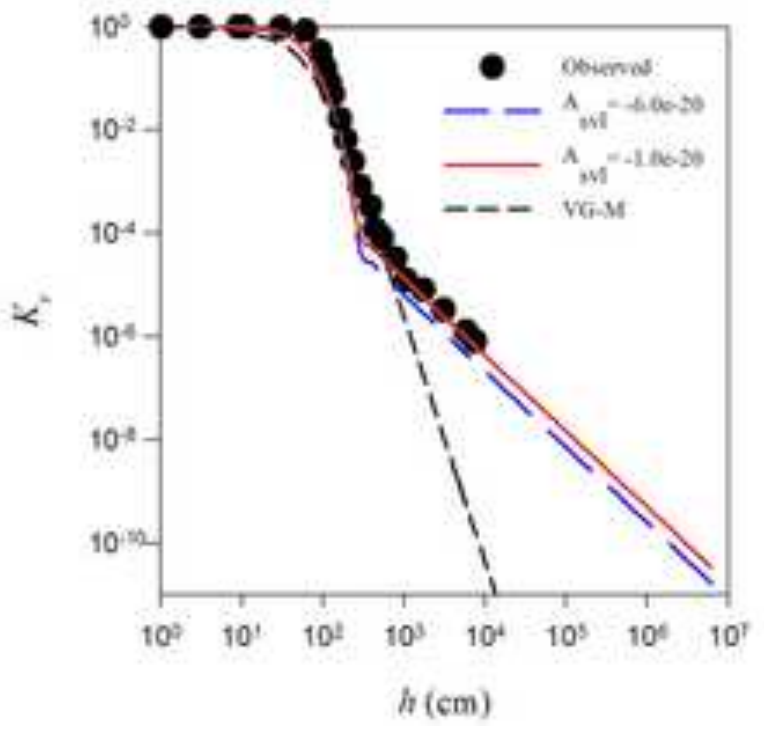

Gilat loam

$\left(\lg K_{p}=1.05 \rho K_{o}+0.12, R^{2}=1.00, n=20\right)$

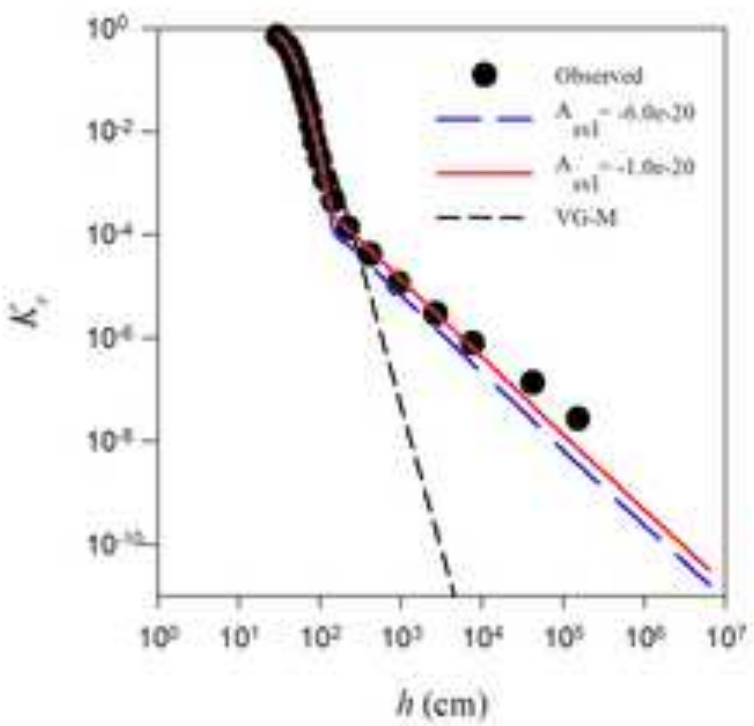

Berlin medium sand 4

$\left(\lg K_{p}=1.04 \lg K_{0}-0.03, K^{2}=0.99, n=7\right)$

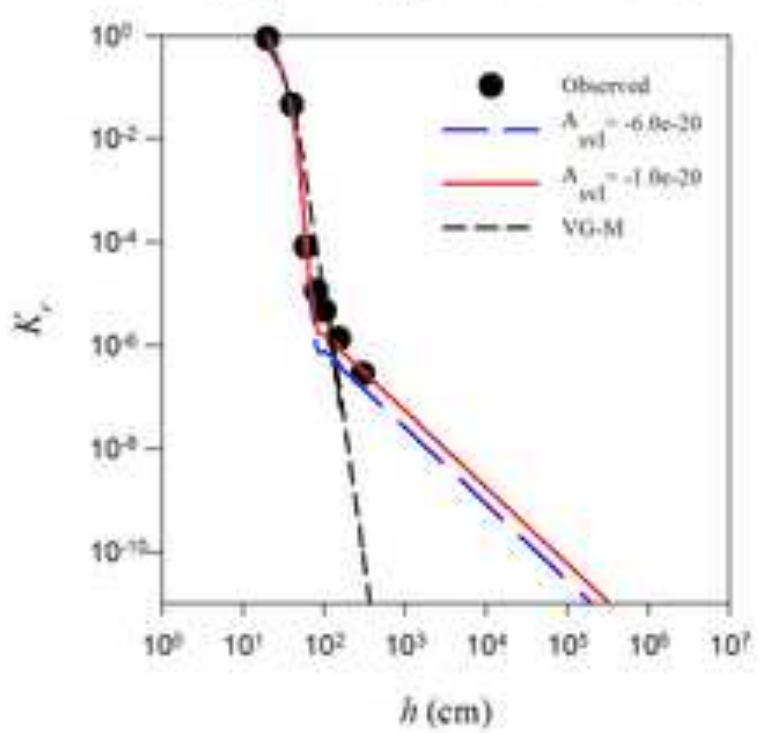

Rohovot sand

$\left(\lg K_{p}=0,96 \lg K_{o}-0,10, R^{2}=0,99, n=23\right)$

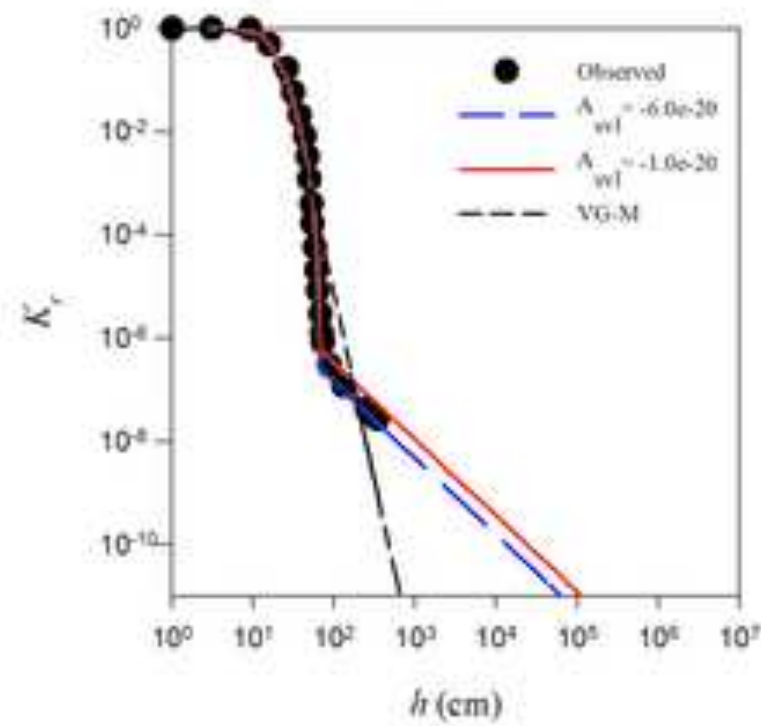

Hupsel sand $\left(\lg K_{p}=0.93 g K_{a}-1.35, R^{2}=0.76, n=15\right)$

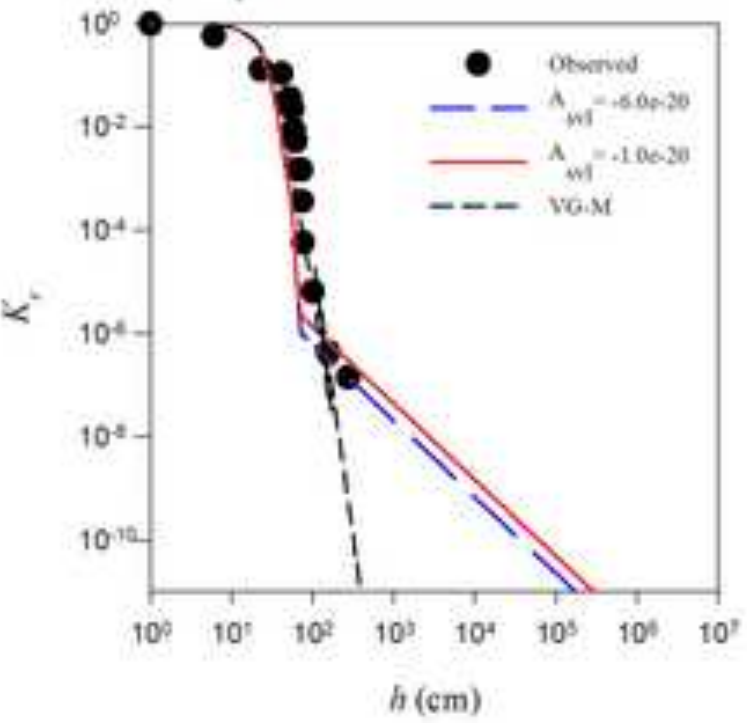




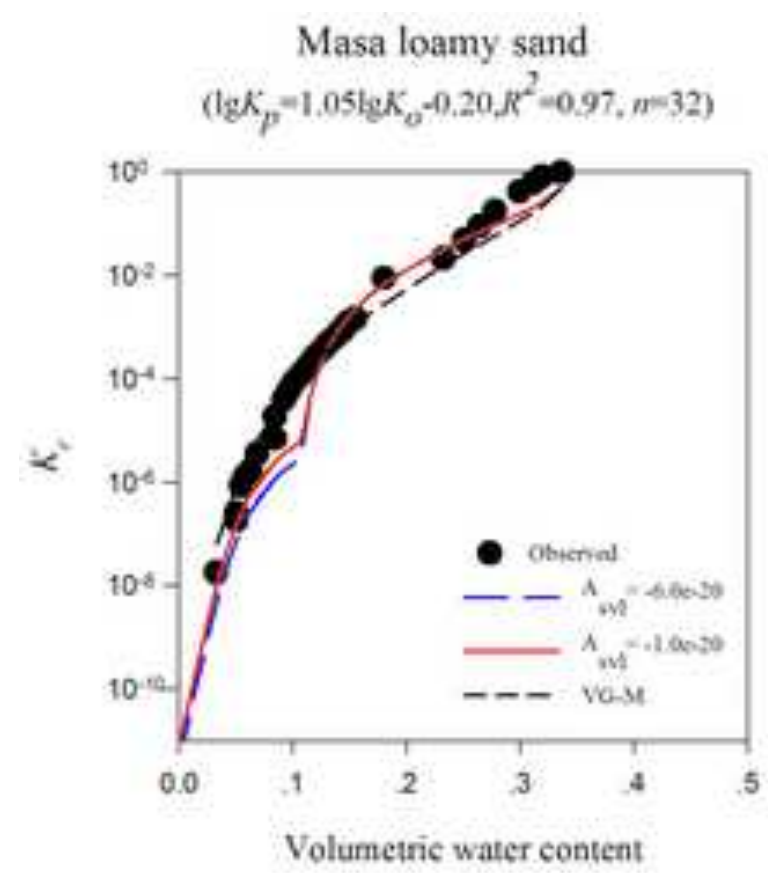

Shonai sand $\left(\lg K_{p}=0,75 \lg K_{o}-1,02, K^{2}=0.88, n=86\right)$

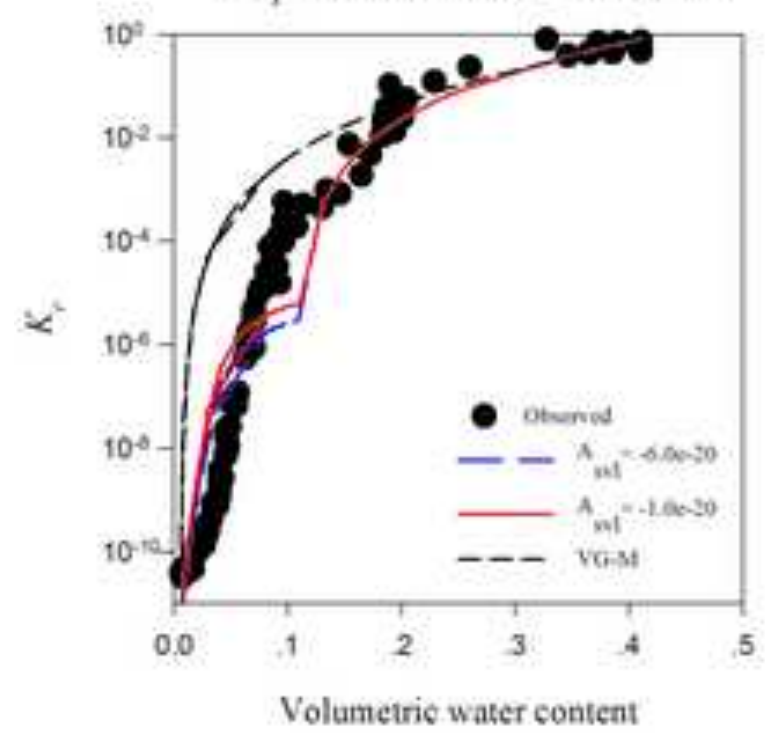

Adelanto loam $\left(\lg K_{p}=1.00 \lg K_{o}-0.49 \cdot R^{2}=0.98, \pi=9\right)$

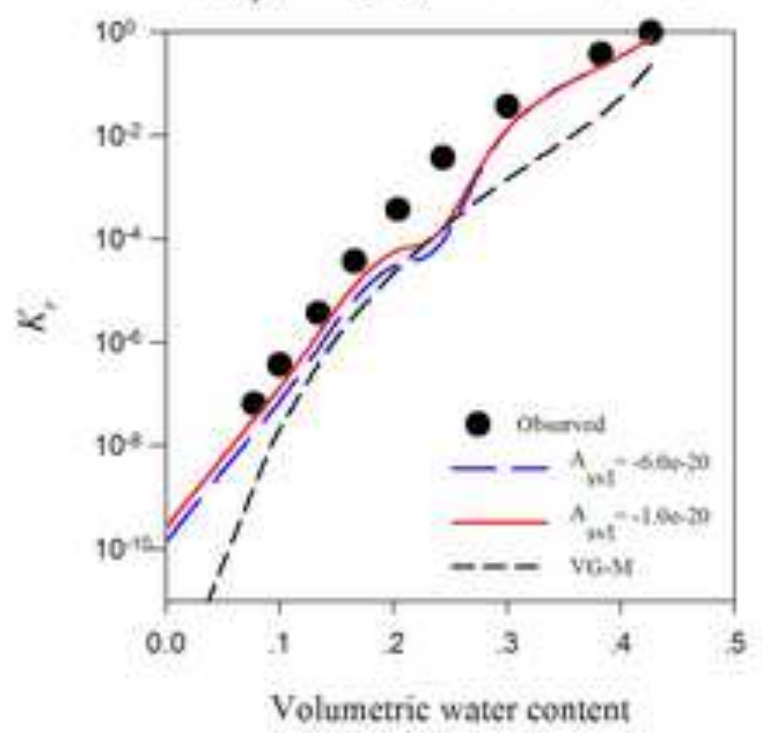

Berlin coarse sand 1 $\left(\lg K_{p}=1,30 \lg K_{o}+0,78, R^{2}=0,92, n=7\right)$

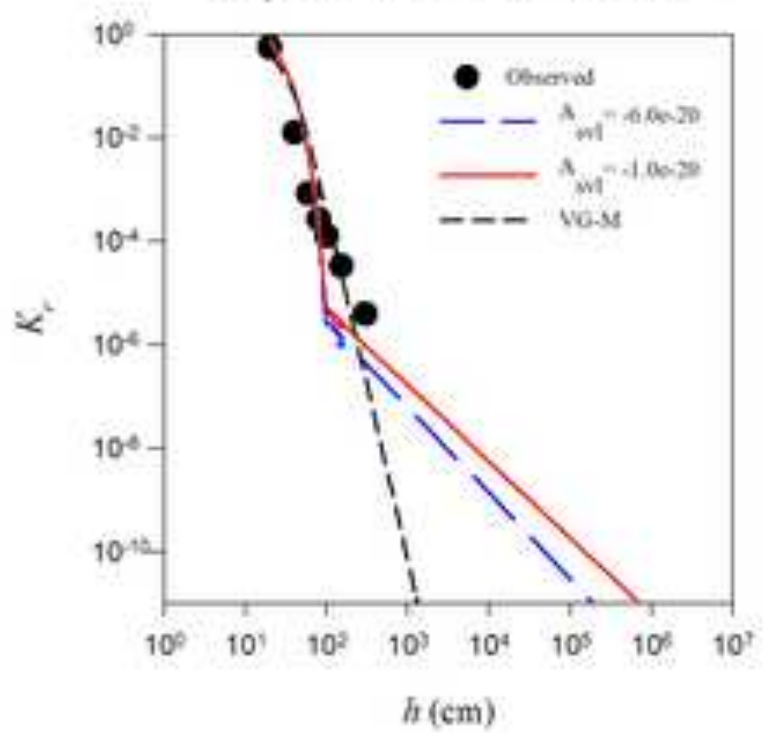

Pachapa loam

(lg $K_{p}=0.93 \lg K_{o}-0,09, R^{2}=0.99, n^{=19}$ )

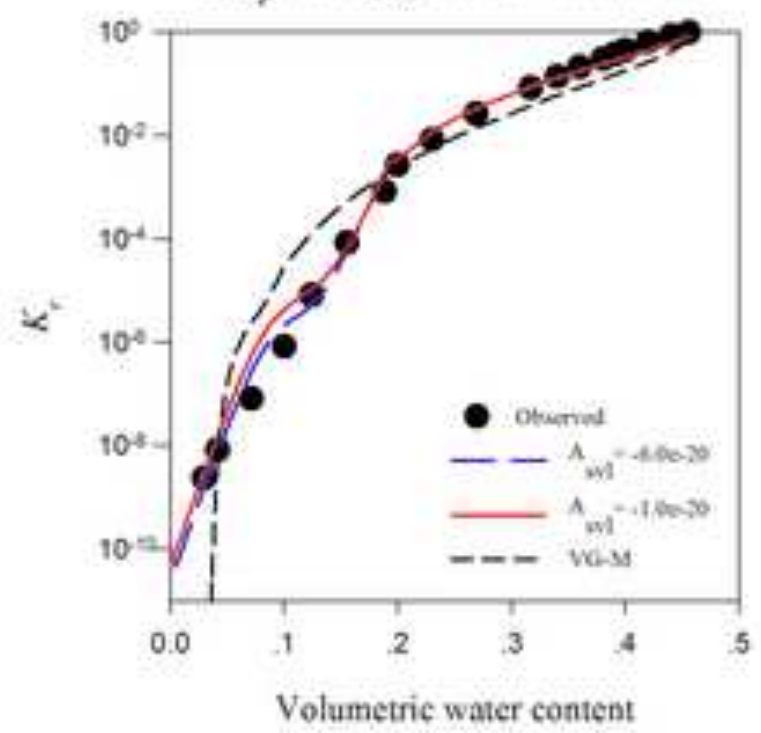

Berlin coarse sand 2

$\left(\mathrm{gg} K_{p}=0.96 \lg K_{o}-0,00, R^{2}=0,97, n=7\right)$

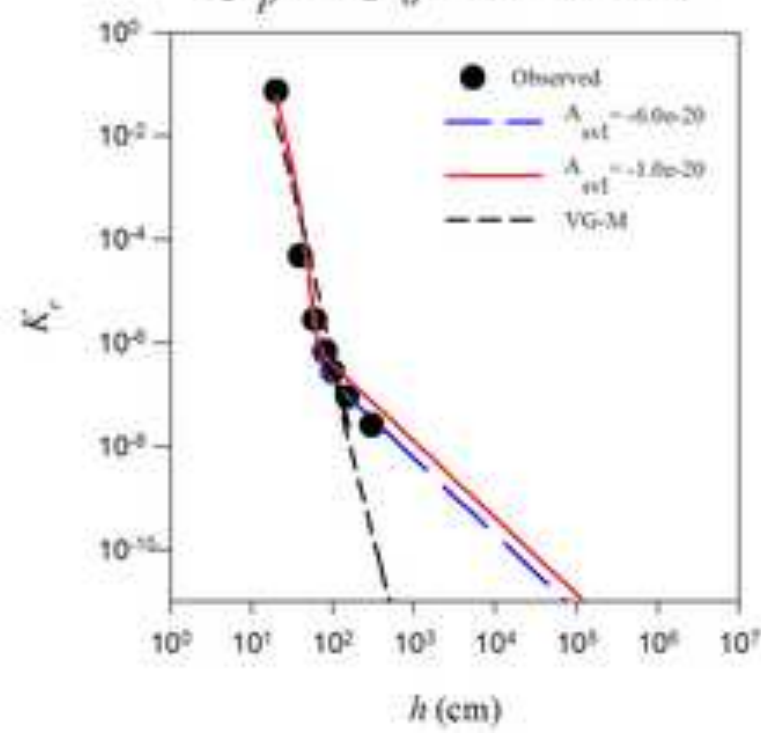


Seelow clay 1 $\left(\lg K_{p}=1.01 \lg K_{o}-0.87, R^{2}=0.98, m^{* 12}\right)$

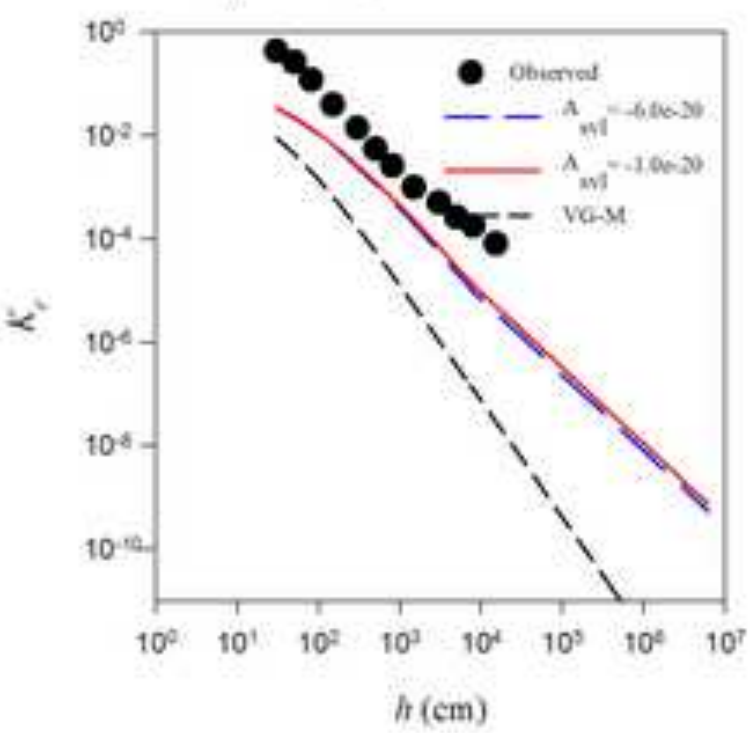

Plumhof sand 2 $\left(\lg K_{p}=1,03 \lg K_{o}-0,37, R^{2}=0,97, n=23\right)$

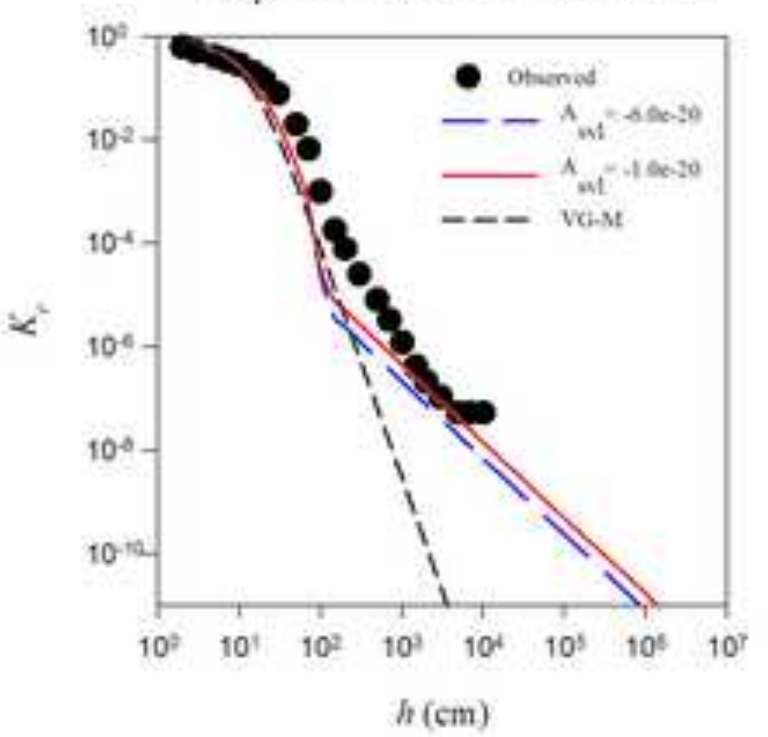

Seclow clay 2 $\left(\lg K_{p}-1.39 \lg K_{o}+1,34, R^{2}=0,93, n=12\right)$

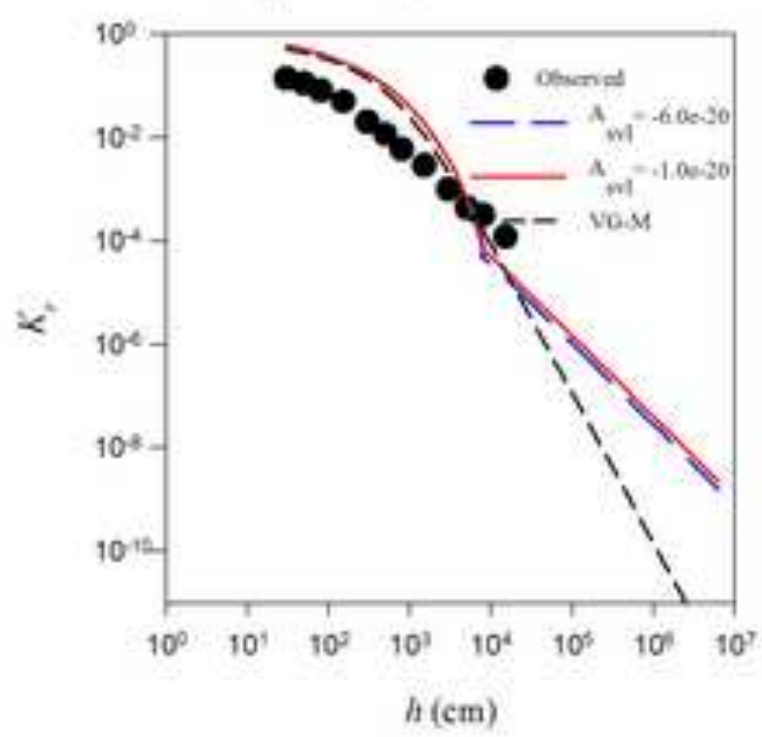

Bordenan sand 1 $\left(\mathrm{g} K K_{p}=0.981 \varrho K_{a}-0.89, R^{2}=0.99, n=24\right)$

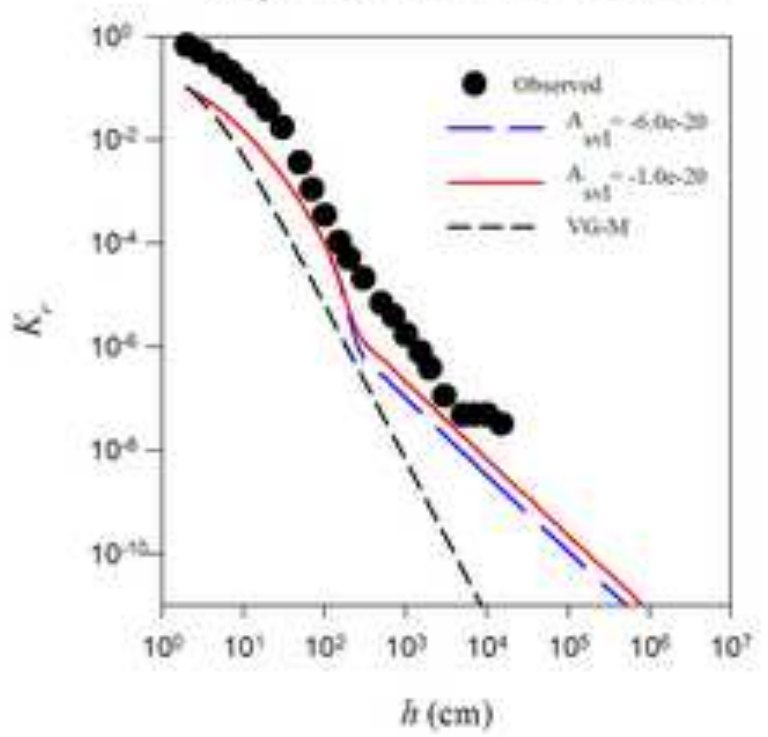

Plumhof sand 1

$\left(\lg K_{p}=1.22 \lg K_{o}+0.59, R^{2}=0.98, n-23\right)$

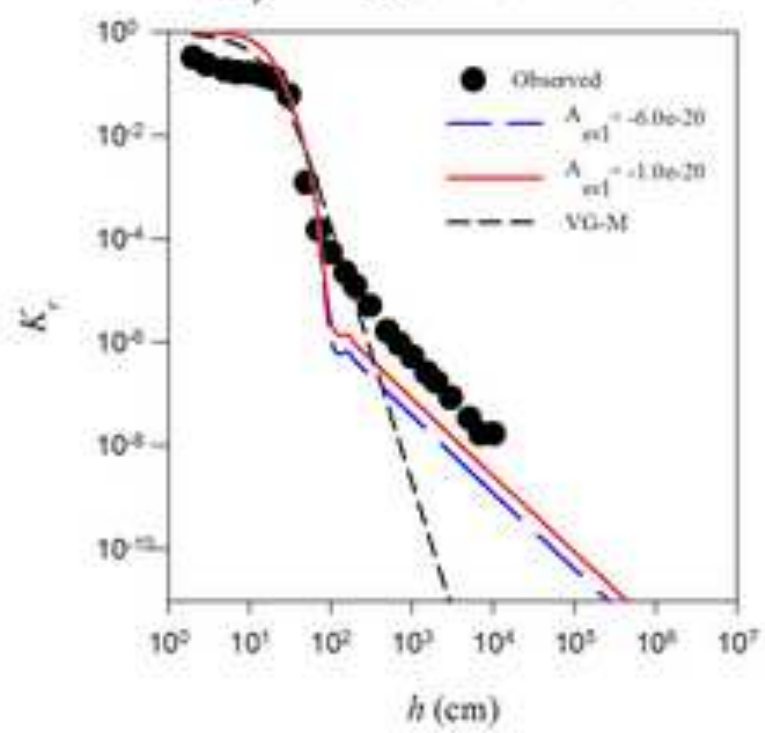

Bordenan sand 2

$\left(\lg K_{p}=1.05 \lg K_{o}-0.58 . R^{2}=0.99, n=24\right)$

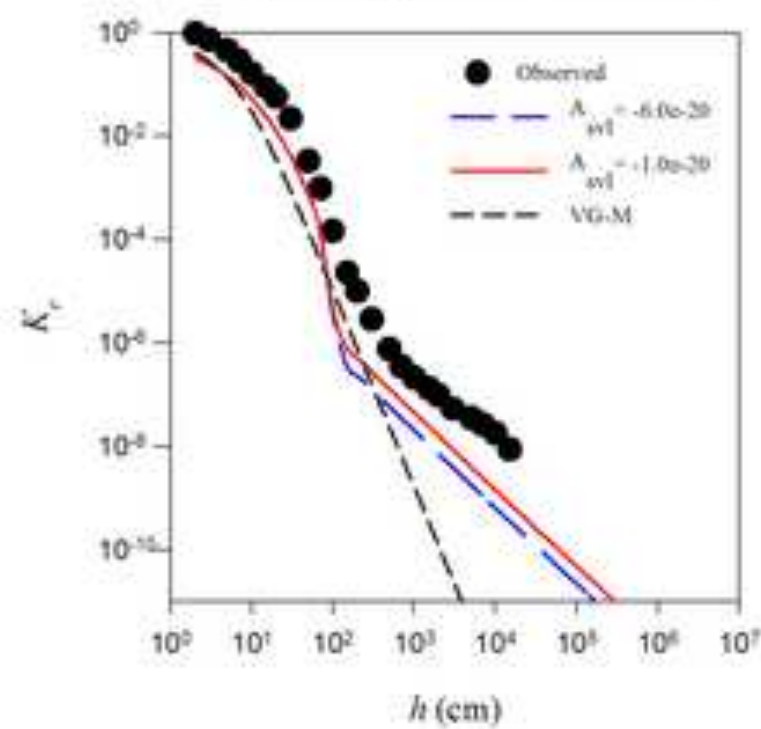


Northen silt

$\left(\operatorname{ig} K_{p}=1,00 \lg K_{o}-0,08, \mathcal{R}^{2}=0,91, n=25\right)$

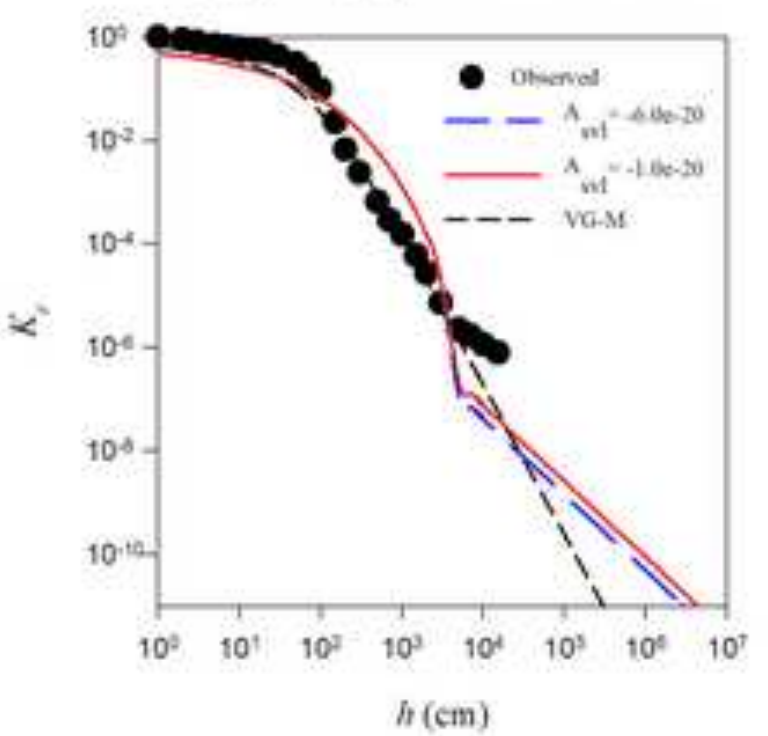

Northen silt loam 3

$\left(\lg K_{p}=1.09 \lg K_{o}+0.03, R^{2}=0.93, n=25\right)$

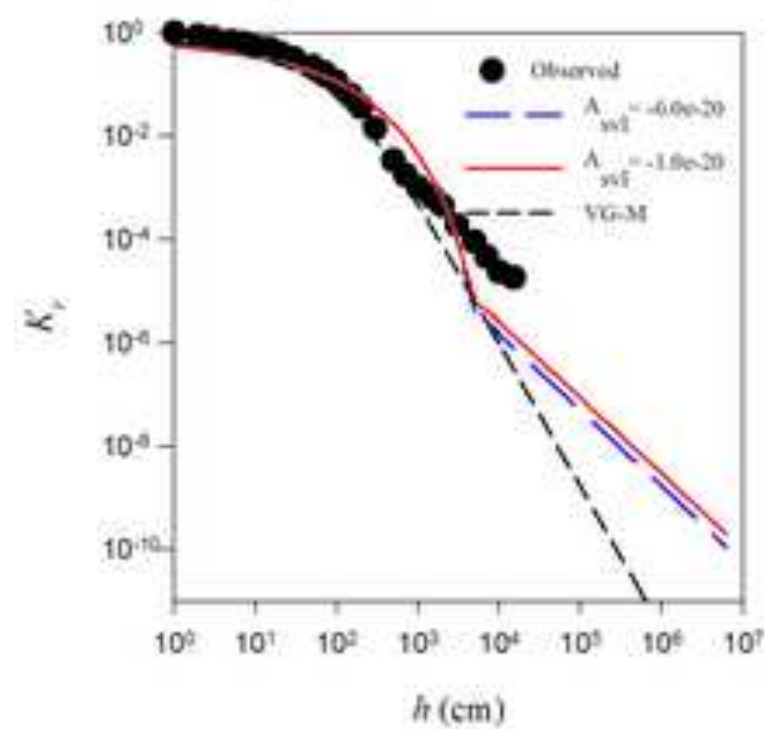

Northen silt loam 1

$\left(\lg K_{p}=\mathrm{L} .11 \lg K_{o}+0.09, K^{2}=0.95, n=25\right.$ )

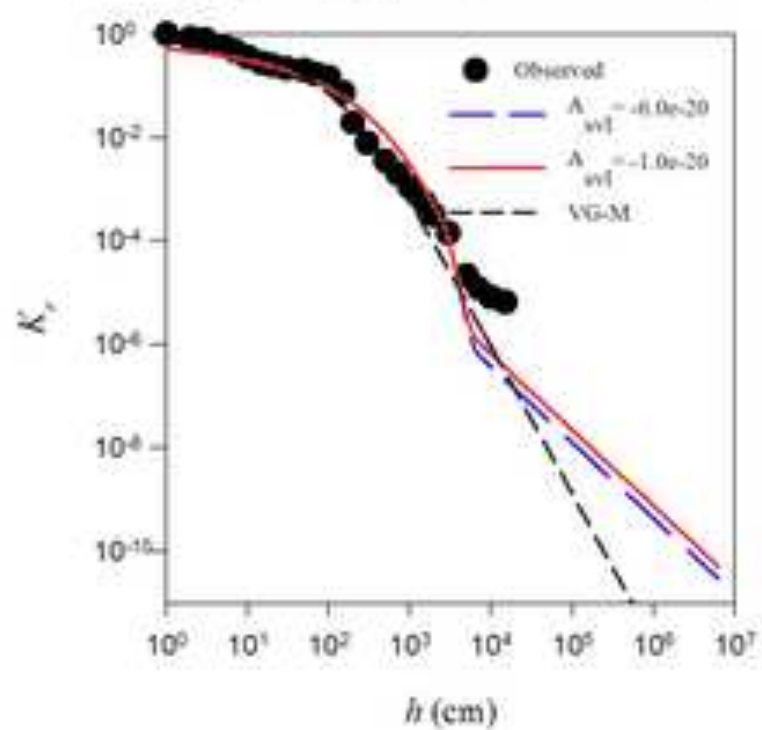

Hollern clay 1 $\left(\lg K_{p}=0.83 \lg K_{o}-0.09, K^{2}=0.97, n=24\right)$

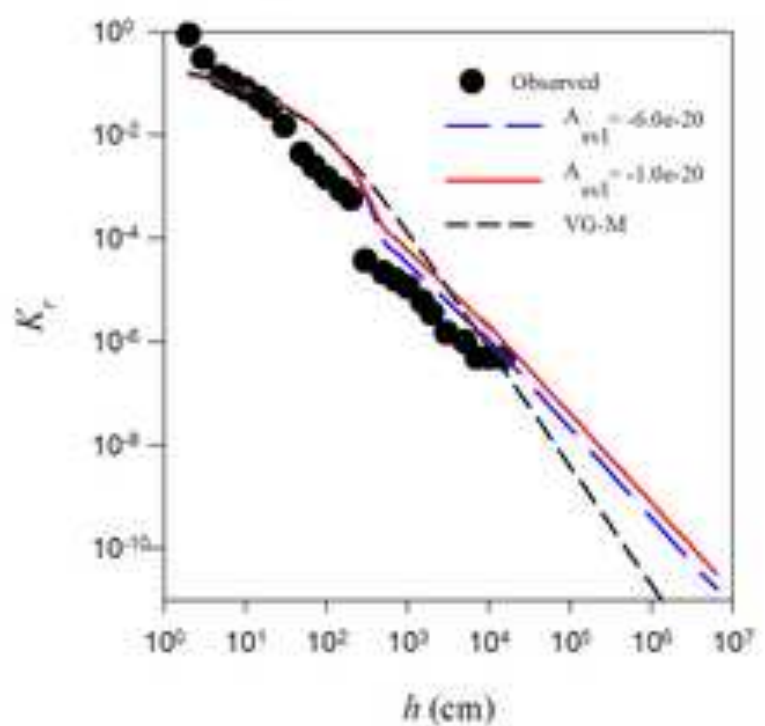

Northen silt loam 2

$\left(\lg K_{p}=0.97 \lg K_{o}-0.52 . R^{2}=0.96, n=25\right.$ )

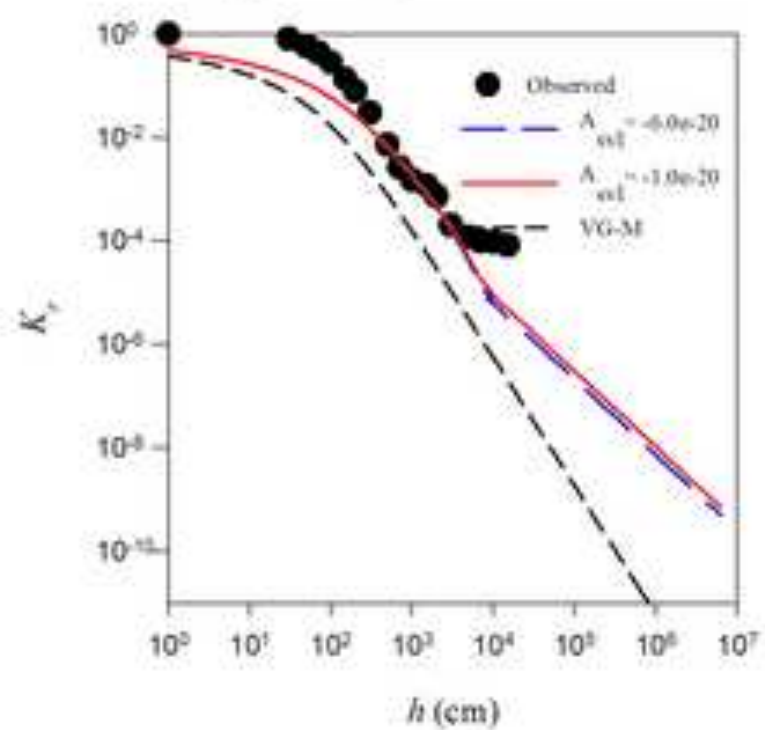

Hollern clay 2

$\left(\lg K_{p}=1.04 \lg K_{o}+0.53, R^{2}=0.79, n=24\right)$

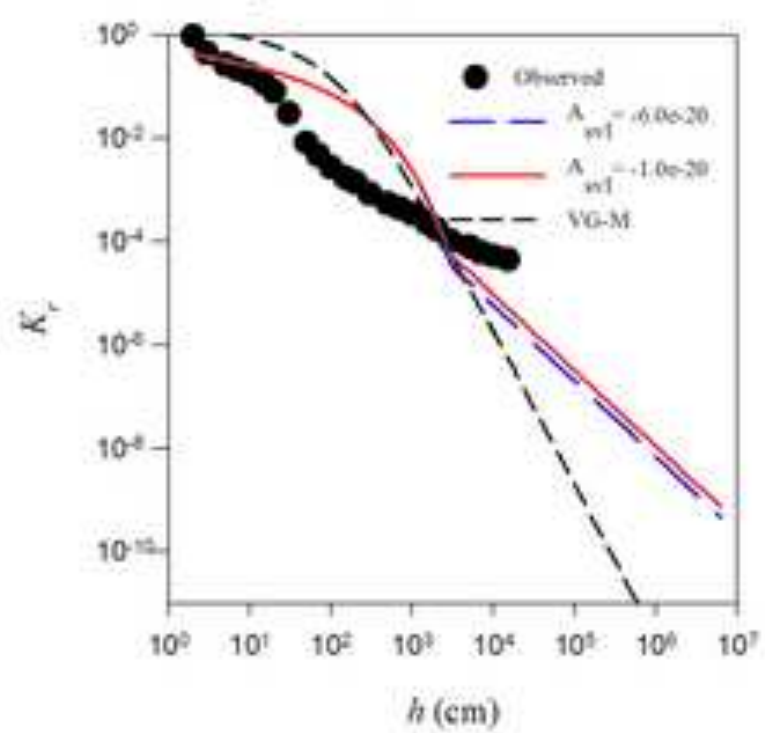



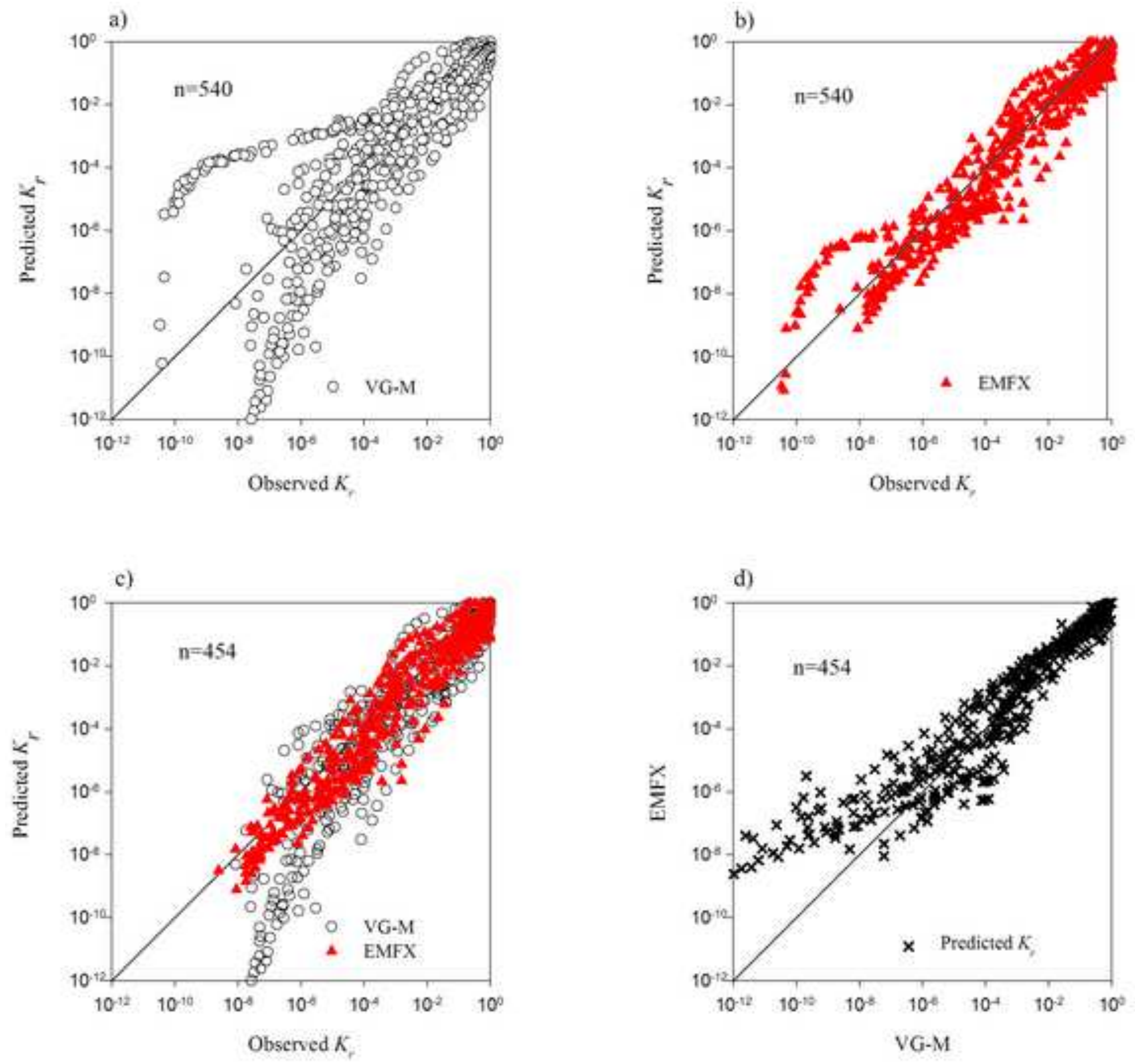